\title{
A Fuzzy Logic Technique for Identifying Nonprecipitating Echoes in Radar Scans
}

\author{
Marc Berenguer, Daniel Sempere-Torres, Carles Corral, and Rafael Sánchez-Diezma \\ Grup de Recerca Aplicada en Hidrometeorologia, Universitat Politècnica de Catalunya, Barcelona, Spain
}

(Manuscript received 9 June 2005, in final form 16 December 2005)

\begin{abstract}
Because echoes caused by nonmeteorological targets significantly affect radar scans, contaminated bins must be identified and eliminated before precipitation can be quantitatively estimated from radar measurements.

Under mean propagation conditions, clutter echoes (mainly caused by targets such as mountains or large buildings) can be found in almost fixed locations. However, in anomalous propagation conditions, new clutter echoes may appear (sometimes over the sea), and they may be difficult to distinguish from precipitation returns. Therefore, an automatic algorithm is needed to identify clutter on radar scans, especially for operational uses of radar information (such as real-time hydrology).

In this study, a new algorithm is presented based on fuzzy logic, using volumetric data. It uses some statistics to highlight clutter characteristics (namely, shallow vertical extent, high spatial variability, and low radial velocities) to output a value that quantifies the possibility of each bin being affected by clutter (in order to remove those in which this factor exceeds a certain threshold).

The performance of this algorithm was compared against that of simply removing mean clutter echoes. Satisfactory results were obtained from an exhaustive evaluation of this algorithm, especially in those cases in which anomalous propagation played an important role.
\end{abstract}

\section{Introduction}

Quality control (QC) is one of the major issues related to improving precipitation estimates from radar measurements. In this context, radar echoes caused by nonmeteorological targets may introduce significant biases in precipitation fields. It is thus necessary to identify and remove these clutter echoes, because insufficiently accurate elimination would have a negative impact not only on the quantitative estimation of precipitation but also on the performance of other automatic algorithms that use radar information for hydrometeorological purposes (e.g., nowcasting techniques based on the extrapolation of radar patterns).

Because of the variation of atmospheric conditions, clutter echoes are constant neither in intensity, vertical extent, nor location [the path of the radar beam is controlled by refractivity and is especially affected by

Corresponding author address: Dr. Marc Berenguer, Grup de Recerca Aplicada en Hidrometeorologia, Universitat Politècnica de Catalunya, Gran Capità, 2-4 (edifici Nexus), despatx 102, Barcelona E-08034, Spain.

E-mail: berengue@grahi.upc.edu variations in the vertical gradient of this variable, see, e.g., Doviak and Zrnic (1992)]. The most severe case occurs when anomalous propagation (AP) of the beam causes it to intersect the ground or sea surface. This phenomenon, known as beam trapping, produces new radar echoes that could be erroneously attributed to precipitation targets. A number of authors (including Battan 1973; Weber et al. 1993; Pratte et al. 1995; Fabry et al. 1997; Steiner and Smith 2002) have described the atmospheric situations most typically associated with AP, mainly related to temperature inversions and negative vertical gradients of humidity.

Steiner and Smith (2002) give an extensive review of the existing techniques for clutter identification or cancellation, focusing in particular on those able to deal with AP situations. These techniques may be grouped in the following different categories (see, e.g., Lee et al. 1995; Meischner et al. 1997; Hannesen 2001):

- those that are based on the use of a mask to remove significant echoes of the mean clutter map (as proposed by Joss and Waldvogel 1990; Pratte et al. 1993; Martín and de Esteban 1994);

- those implemented in the signal processor, which are mainly based on the analysis of pulse-to-pulse signal 
fluctuation in noncoherent radars or on the analysis of Doppler velocity estimates in coherent radars (see, among others, Aoyagi 1983; Keeler and Passarelli 1990; Doviak and Zrnic 1992; Nicol et al. 2003); or

- those applied after signal processing, based on the combined analysis of statistics derived from radar measurements (usually known as features), which highlight the characteristics of nonprecipitating echoes.

Mean clutter masks are not effective at identifying clutter in significant AP situations because trapping echoes appear in areas that are usually clutter free. Some authors (Lee et al. 1995; Andersson et al. 1997; Grecu and Krajewski 2000) have pointed out that Doppler techniques by themselves are not enough in some cases because of their difficulties in distinguishing between clutter and areas of rainfall with near-zero radial velocities. Moreover, in cases of beam trapping over the sea, Doppler techniques have some limitations because sea waves may present velocities significantly different from zero, and thus beam-trapping echoes over the sea cannot easily be removed using these techniques (see, e.g., Andersson et al. 1997; Hannesen 2001).

A number of studies have proposed techniques from the third category. They use various statistics derived from radar measurements that highlight the characteristics of clutter echoes that best differentiate them from precipitation (mainly shallow vertical extent, a high degree of spatial variability, and velocities close to zero). Most of these algorithms are based on a pixel-by-pixel analysis [with the notable exception of the Weather Surveillance Radar-1988 Doppler (WSR-88D) algorithm (Fulton et al. 1998), which rejects the first plan position indicator (PPI) for the purposes of retrieving precipitation when a significantly higher number of echoes affect it than the second tilt, on the assumption that it is affected by AP clutter]. These algorithms can be grouped into the following two classes: 1) those based on decision trees, and 2) those that use more complex techniques based on probabilistic analysis, fuzzy logic, or neural networks [these concepts are reviewed in Kosko (1992)]. The main difference between these two classes lies in the way in which the features take part in the clutter-identification scheme. In decision-tree algorithms, features are analyzed according to a logical chain by means of thresholds, whereas in the techniques from the second group features are implemented in a combined, rather than a sequential, manner.

This is the case for the methodology proposed by Moszkowicz et al. (1994), which is based on a comparison between the estimated probability values of each radar bin being affected only by precipitation and those contaminated by clutter. These probability values are estimated using the joint distribution function of a number of features, which was assumed to be Gaussian.

Some other techniques [the AP detection algorithm (Pratte et al. 1997; Kessinger et al. 2001, 2003), and the algorithm included in the McGill Radar Data Analysis, Processing, and Interactive Display (RAPID) radar data processing system (Bellon and Kilambi 1999, recently updated by Lee et al. 2005)] are based on fuzzy logic. These two algorithms have a similar philosophy: they are based on deriving, at each radar bin, a value in the range $[0,1]$ that quantifies the possibility of the bin being contaminated by clutter. The main difference between them lies in the set of features used in each one.

Other authors have chosen to implement neural network schemes for classifying radar echoes. This is the case for the algorithm, proposed by Grecu and Krajewski (2000), whose performance was studied over a large dataset by Krajewski and Vignal (2001). Similarly, da Silveira and Holt (2001) proposed an alternative neural network algorithm in which they only used two features obtained from measurements taken by a polarization diversity radar.

The main objective of this study is to develop and evaluate a technique for clutter identification that performs well in AP situations. The technique we propose uses fuzzy logic concepts. This makes it conceptually very simple and avoids the difficulties of establishing the complex relationships between features and calibrating the different thresholds required in decisiontree schemes (a large number of features, more than three or four, may be easily implemented in fuzzy logic techniques). Similarly, the recalibration of fuzzy logic algorithms (for implementation in a new radar) is simpler than it is with decision-tree algorithms.

Furthermore, because of the significant differences that some authors have observed between ground and sea clutter echoes (see, e.g., Andersson et al. 1997; Steiner et al. 1999), the proposed algorithm is applied using one configuration over the ground and one over the sea.

Section 2 presents the region where we applied the algorithm and characterizes it in terms of clutter occurrence. Section 3 reviews the features used in the literature for clutter discrimination and analyzes the applicability of some of them for this purpose. The proposed algorithm is described in section 4 , and the results of its implementation are presented in section 5 .

\section{Environment of study}

This study was carried out in the vicinity of Barcelona, Spain (see Fig. 1). In the Mediterranean area, at 


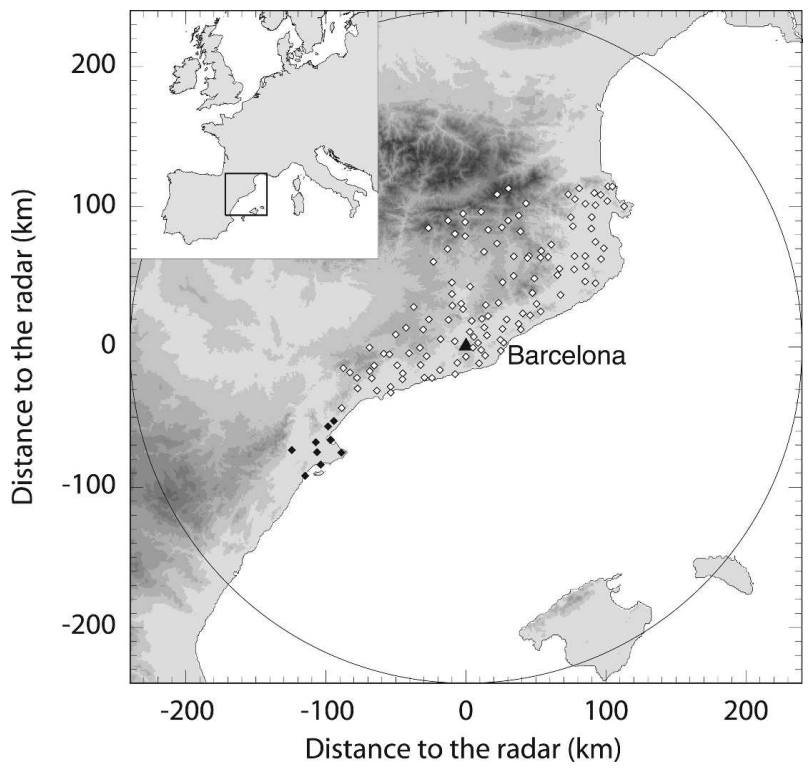

FIG. 1. Domain where this study has been carried out. Black triangle shows the location of the Corbera de Llobregat C-band radar, white diamonds correspond to the location of the rain gauges of the ACA network, and black diamonds to the rain gauges of the SMC network.

the end of summer, mountain ranges near the coast act as natural barriers causing the updraft of warm, moist air from the sea, which encourages the generation of intense local convective storms. However, stratiform systems are also common, especially in winter and spring.

The radar data used in this study were collected using the C-band radar of the Spanish Institute of Meteorology [Instituto Nacional de Meteorología (INM)] located in Corbera de Llobregat (its technical characteristics are summarized in Table 1). This system performs two volumetric scans every $10 \mathrm{~min}$-one measuring only reflectivity ("normal" mode) and one measuring both reflectivity and radial velocity (Doppler mode). In this study, raw reflectivity data were only corrected for mountain-screening effects [with the methodology proposed by Delrieu and Creutin (1995), based on calculating the shielded power by means of a digital elevation model] before clutter identification.

We also used measurements from the automatic network of rain gauges of the Catalan Water Agency [Agència Catalana de l'Aigua (ACA)], which partially covers the area of study, to contrast the results obtained with the proposed clutter-identification algorithm.

\section{a. Calibration dataset}

We used a dataset composed of 200 radar scans taken between 1999 and 2004 to calibrate the developed fuzzy
TABLE 1. Main characteristics of the C-band $\operatorname{radar}(\lambda=5.3 \mathrm{~cm})$ used in this study (located in Corbera de Llobregat, near Barcelona)

\begin{tabular}{lcc}
\hline \multicolumn{1}{c}{ Frequency } & \multicolumn{2}{c}{$5620 \mathrm{MHz}$} \\
Pulse length & \multicolumn{2}{c}{$2 \mu \mathrm{s}$} \\
\multicolumn{1}{c}{ Beamwidth (3 dB) } & \multicolumn{2}{c}{$0.9^{\circ}$} \\
\multicolumn{1}{c}{ Heak power } & \multicolumn{2}{c}{$250 \mathrm{~kW}$} \\
\hline \multicolumn{2}{c}{$664 \mathrm{~m}($ AMSL) } \\
\hline Azimuthal resolution & $0.86^{\circ}$ & $0.86^{\circ}$ \\
Radial resolution & $2 \mathrm{~km}$ & $1 \mathrm{~km}$ \\
PRF & $250 \mathrm{~Hz}$ & $900 / 1200 \mathrm{~Hz}$ \\
Pulse length & $2 \mu \mathrm{s}$ & $0.5 \mu \mathrm{s}$ \\
Maximum range & $240 \mathrm{~km}$ & $120 \mathrm{~km}$ \\
Nyquist velocity & - & $48 \mathrm{~m} \mathrm{~s}$ \\
No. of elevations & 20 & 8 \\
Lowest elevation & $0.5^{\circ}$ & $0.5^{\circ}$ \\
Highest elevation & $25^{\circ}$ & $11^{\circ}$ \\
\hline
\end{tabular}

logic algorithm (see section 4). These data, which include a wide variety of propagation and meteorological situations, were analyzed by an expert who manually identified all clutter-contaminated bins.

\section{b. Clutter climatology}

Bech et al. (2002) characterized the propagation conditions in the region of the study and concluded that summer, especially August, is the season most affected by superrefraction (which is responsible for beam trapping) and is when propagation shows the highest variability.

The manually edited radar scans from the calibration dataset provided valuable information about the areas most affected by AP clutter. A map showing the frequency with which different areas were affected by clutter was derived by dividing the number of scans in which each bin has been labeled as clutter by the total number of scans. This map (Fig. 2) shows that in addition to mean clutter echoes, ground clutter associated with AP is frequent in certain areas: in some parts of the southern coast and in the mountain range of Mallorca, clutter echoes affected $5 \%-25 \%$ of the analyzed scans. Despite the low frequencies with which sea clutter is detected $(0.5 \%-5 \%$ of the analyzed scans), it affects a significant area.

\section{Features used for clutter discrimination}

Features are statistics derived from radar measurements that are expected to highlight the differences between clutter and precipitation echoes. This section first reviews the features usually implemented in different clutter-identification techniques found in the litera- 


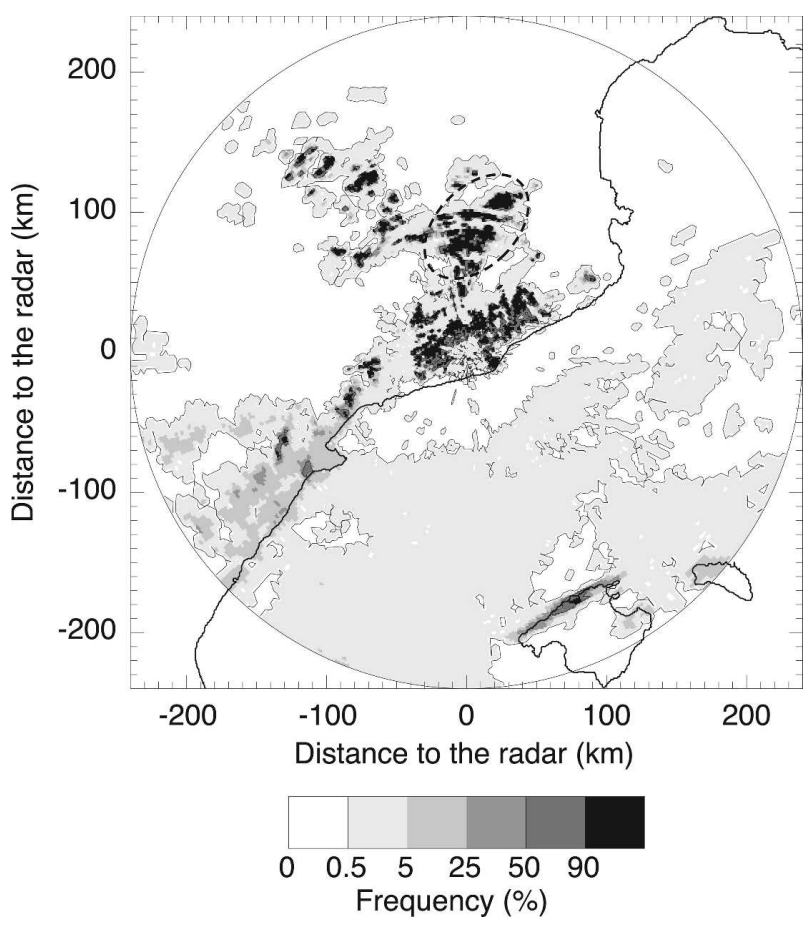

FIG. 2. Clutter frequency map derived from the radar dataset described in section $2 \mathrm{a}$, which has been manually analyzed by an expert. The dashed-line ellipse encloses one of the biggest and most intense ground echoes that affect the first PPI in MP conditions.

ture and then characterizes some of these statistics by their distribution functions.

\section{a. Review of features used for clutter discrimination}

As mentioned above, some characteristics of clutter echoes allow an expert to distinguish them from meteorological returns. To make this identification process automatic, different features found in the literature are used to highlight these characteristics.

The vertical extent of the reflectivity pattern is one example. In both mean propagation (MP) and AP conditions, clutter echoes only affect the lowest radar tilts. Therefore, the echo top (i.e., the vertical extent of radar echoes) in clutter regions not affected by precipitation is limited to the lowest elevations. For this reason, a number of authors (Moszkowicz et al. 1994; Rosenfeld et al. 1995; Kulie et al. 1999; Grecu and Krajewski 2000; Steiner and Smith 2002) have used it as a feature that characterizes clutter. Moszkowicz et al. (1994) and Grecu and Krajewski (2000) also used the height of the maximum echo above the pixel location as a feature that characterizes the development of the analyzed echo. Finally, Grecu and Krajewski (2000) proposed the bin range as a feature (in principle, the farther the bin, the higher it is, and, thus, the lower the probability of being affected by clutter).

Another feature that characterizes the shallow extent of clutter is the vertical gradient of reflectivity: even when precipitation affects significant clutter areas (large mountains), the negative values of the vertical gradient of reflectivity tend to be high [this feature is used in the techniques proposed by Moszkowicz et al. (1994), Lee et al. (1995), Andersson et al. (1997), Bellon and Kilambi (1999), Steiner and Smith (2002), and Lee et al. (2005)].

The reflectivity field tends to show a high degree of variability in areas affected by clutter (compared to precipitation). Certain statistics that characterize this variability have thus been used to characterize clutter. One example is the spin change, which was proposed by Smith et al. (1996) and has been used by Grecu and Krajewski (2000), Steiner and Smith (2002), and Kessinger et al. (2003). Some authors (Rosenfeld et al. 1995; Bellon and Kilambi 1999; Grecu and Krajewski 2000) opted for the local horizontal gradient. Less-used features include the texture of reflectivity (Kessinger et al. 2003), the local standard deviation of reflectivity (Lee et al. 2005), the reflectivity sign [conceptually similar to the spin change (Kessinger et al. 2003)], and the coefficient of variation (Grecu and Krajewski 2000).

In radars with Doppler capability, radial velocity may be useful for discriminating clutter, because it tends to have low velocities. It is implemented in many of the reviewed techniques [see Giuli et al. 1991; Lee et al. 1995; Bellon and Kilambi 1999; Kessinger et al. 2003 (in this case, together with spectral width); and Lee et al. 2005]. As an alternative to Doppler measurements, Grecu and Krajewski (2000) used velocity fields obtained from consecutive reflectivity scans with a correlation technique.

A number of studies also showed that clutter signal fluctuates in time less than precipitation. Therefore, Lee et al. (1995) included the difference between two consecutive samples at the same bin in their decision tree for characterizing clutter. Similarly, Michelson and Andersson (1995) proposed calculating the root-meansquare variation of the series of the most recent five radar maps (to highlight areas that change rapidly).

In some approaches (Moszkowicz et al. 1994; Kulie et al. 1999; Grecu and Krajewski 2000) reflectivity has also been used to characterize clutter. Grecu and Krajewski (2000) warned that this feature by itself might be of little interest, but they expected it to have some value when used in conjunction with other features.

Other studies have evaluated the usefulness of multiple polarization measurements for discriminating clutter. One of the steps of the decision tree proposed by 

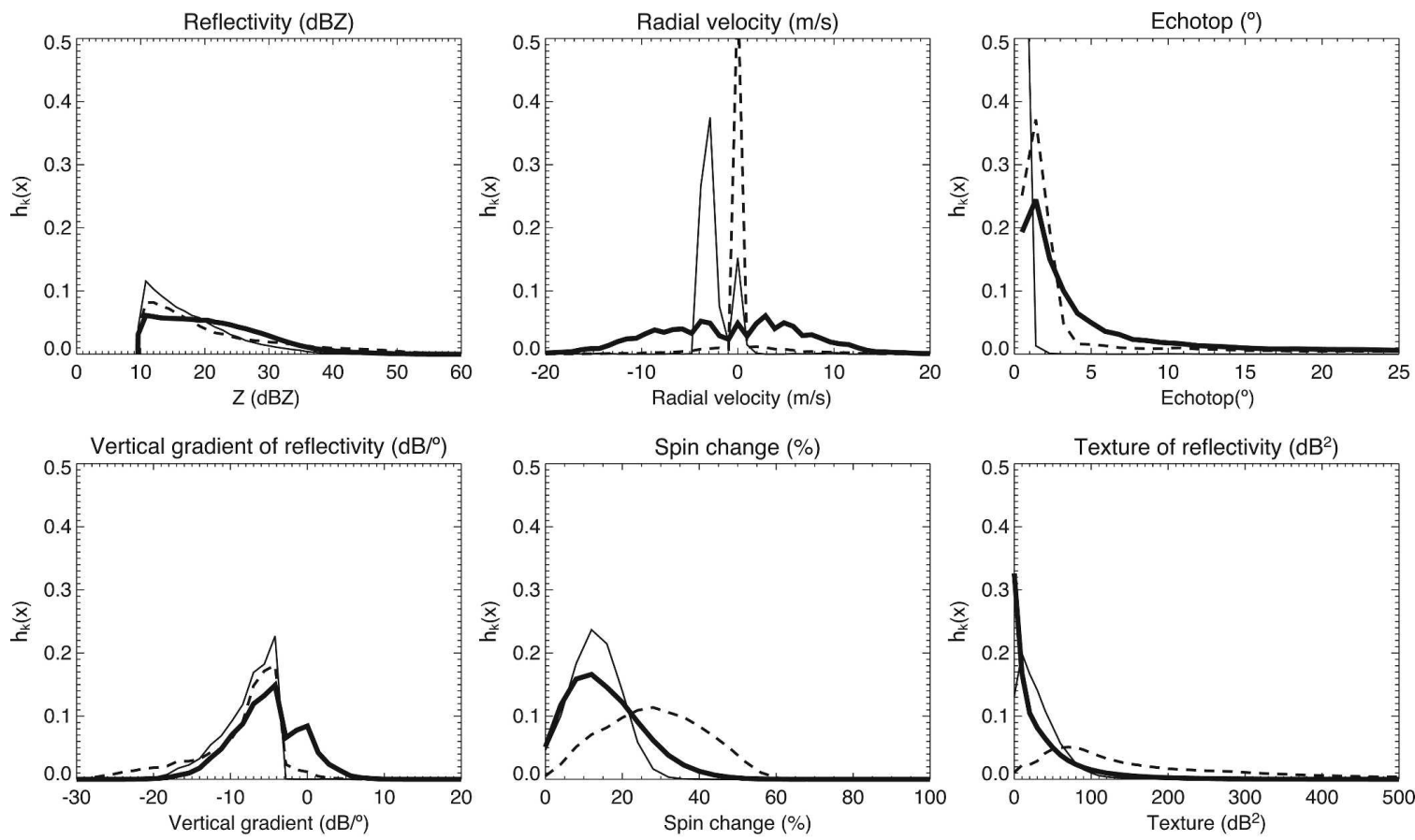

Precipitation - - - - - Ground clutter _ Sea clutter

FIG. 3. Feature histograms $h_{k, e}(x)$ corresponding to precipitation (thick line), ground clutter (dashed line), and sea clutter (thin line), derived from the radar dataset described in section $2 \mathrm{a}$, which has been manually analyzed by an expert.

Giuli et al. (1991) involves comparing three variables: the horizontal polarization reflectivity $Z_{\mathrm{H}}$, the differential reflectivity $Z_{\mathrm{DR}}$, and the spatial variability of $Z_{\mathrm{DR}}$. Ryzhkov and Zrnic (1998) proposed using the cross correlation between horizontally and vertically polarized returns $\rho_{\mathrm{HV}}$, because clutter is assumed to produce lower values of $\rho_{\mathrm{HV}}$ than precipitation. On the other hand, da Silveira and Holt (2001) worked with a circular polarization radar and used the circular depolarization ratio (corrected for propagation effects) and the modified degree of polarization as features to discriminate clutter with their neural network technique.

Finally, some authors have used radar data combined with other sources of information. For example, Fiore et al. (1986) used infrared satellite images to distinguish cloud-free areas with significant radar echoes. Similarly, Pamment and Conway (1998) also used satellite information together with surface reports and lighting information.

\section{b. Feature distribution functions}

This section assesses the potential of several features frequently used to identify clutter echoes (those used in the proposed algorithm; see section 4) by analyzing the sample distribution functions derived from the calibra- tion dataset (where all radar echoes have been manually labeled as clutter or precipitation).

The features we have chosen are the radar measurements themselves (both reflectivity and Doppler velocity) and the following derived statistics: the echo top (expressed as the elevation angle of the highest PPI containing reflectivity measurements over $10 \mathrm{dBZ}$ ), the vertical gradient of reflectivity [derived from the lowest two PPIs $\left(\mathrm{dB} \mathrm{deg}^{-1}\right)$ ], the spin change [calculated as described by Steiner and Smith (2002) (\%)], and the texture of reflectivity [obtained using the expression given by Kessinger et al. (2003) $\left.\left(\mathrm{dB}^{2}\right)\right]$.

Figure 3 presents the frequency distributions for each feature $X_{k}$, conditional to the echo type $e$ (ground clutter, sea clutter, and precipitation), which have been derived according to Eq. (1) (similar curves were presented by Steiner et al. 1999; Grecu and Krajewski 2000; Lee et al. 2005),

$$
\begin{aligned}
h_{k, e}(x) & =p\left[X_{k}=x \mid \text { echo type }=e\right] \\
& =\frac{n\left(X_{k}=x \cap \text { echo type }=e\right)}{n(\text { echo type }=e)},
\end{aligned}
$$

where $n\left(X_{k}=x \cap\right.$ echo type $\left.=e\right)$ stands for the number of bins where $X_{k}=x$ and the echo has been classified 

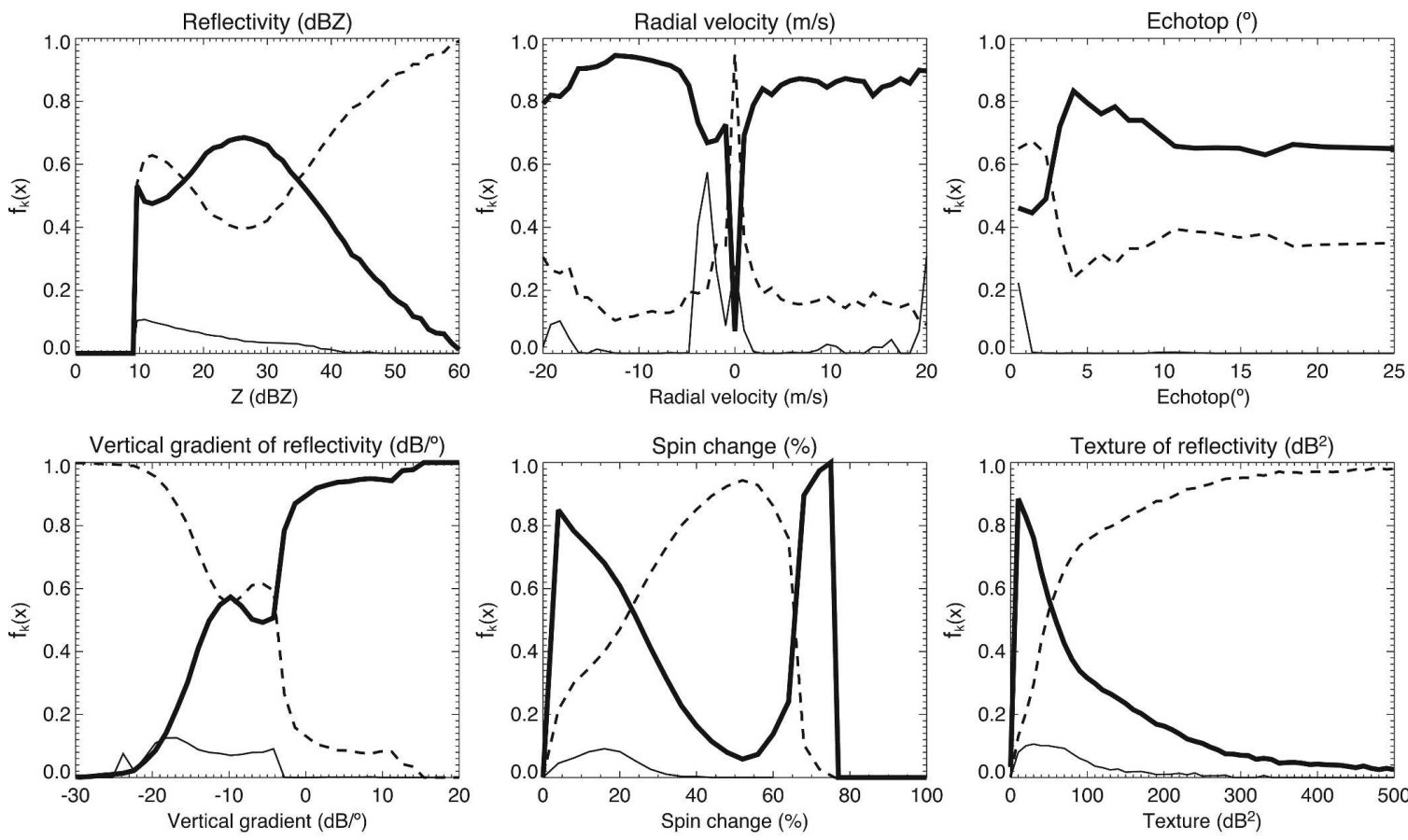

Precipitation - . - _ - Ground clutter

Sea clutter

FIG. 4. Conditional probability curves $f_{k, e}(x)$ corresponding to precipitation (thick line), ground clutter (dashed line), and sea clutter (thin line) derived from the radar dataset described in section 2a, which has been manually analyzed by an expert.

as type $e ; n($ echo type $=e)$ is the total number of bins classified as echo type $e$.

We can also derive the conditional probability of a bin being affected by a certain echo type $e$ when, there, $X_{k}=x$. Equation (2) may be used to obtain the sample conditional probability function derived from the set of analyzed radar scans (see Fig. 4),

$$
\begin{aligned}
f_{k, e}(x) & =p\left[\text { echo type }=e \mid X_{k}=x\right] \\
& =\frac{n\left(X_{k}=x \cap \text { echo type }=e\right)}{n\left(X_{k}=x\right)},
\end{aligned}
$$

where $n\left(X_{k}=x\right)$ is the total number of bins where $X_{k}=x$.

Figures 3 and 4 show that some ground clutter echoes have higher reflectivities than sea clutter or even precipitation. This is the case for echoes caused by large mountains and for very intense beam-trapping echoes (both may exceed $40 \mathrm{dBZ}$ ). Furthermore, while ground echoes tend to have radial velocities close to zero, sea clutter may have a wider range of values (the negative bias in the figures could be related to a prevailing wind direction caused by synoptic conditions prone to AP; however, the small number of Doppler scans with sea clutter in the analyzed dataset does not allow us to draw a firm conclusion). While the echo top of sea clutter exceeds the second tilt $\left(1.4^{\circ}\right.$ in the scanning mode of the studied radar) in only a few cases, ground clutter echoes present a greater extent (some of them affect higher tilts and are more frequently embedded in precipitation than sea clutter) and precipitation patterns may have significant vertical development. Finally, ground clutter tends to show more spatial variability than precipitation or sea clutter (as shown in the graphs on the spin change and the texture of reflectivity).

The shapes of the various distributions shown in Fig. 3 are somewhat similar to those of the histograms derived by Steiner et al. (1999) from the analysis of eight radar scans from different WSR-88D radars (i.e., in climatic regions significantly different from the area studied here). Therefore, the conclusions of this analysis are similar: although all of the features analyzed have some ability to discriminate clutter from precipitation, none of them seems to be sufficient when used alone, and thus we chose to combine them in an algorithm based on fuzzy logic.

\section{The proposed algorithm}

The aim of this study is to develop a flexible algorithm that can identify nonprecipitating echoes in radar 
reflectivity scans, especially in cases of AP. The technique we have developed is based on fuzzy logic concepts (following the ideas of those proposed by Bellon and Kilambi 1999 and Kessinger et al. 2003). These techniques have proven to be flexible and can combine different features.

This algorithm is the simplest form of a "fuzzy classifier" (Mendel 1995); at each radar bin, it assesses the possibility of the measurement being contaminated by clutter by associating a value in the range $[0,1]$ from the joint analysis of a number of features. To do this, we use a set of user-defined one-dimensional curves (known as membership functions) $\mu_{k}(x)$, which quantify the expectation that bins where the feature $X_{k}=x$ will be affected by clutter. Therefore, by combining the membership functions with the feature fields $X_{k}$, we obtain $Y_{k}\left(r_{i}, \theta_{j}\right)=\mu_{k}\left[X_{k}\left(r_{i}, \theta_{j}\right)\right]$ at each bin, where $r_{i}$ and $\theta_{j}$ stand for the polar coordinates. Finally, a field $Y$ is obtained as the weighted average of fields $\mathrm{Y}_{k}$, according to a set of weights $w_{k}$. Radar bins in which $Y$ exceeds a certain threshold (typically 0.5 ) are considered contaminated by clutter and thus are removed.

\section{a. Implemented features}

The features used in the algorithm are those presented in section 3b: radar measurements (both reflectivity and Doppler velocity) and the fields for echo top, the vertical gradient of reflectivity, spin change, and texture of reflectivity. Individually, these features have shown some ability to characterize clutter echoes. By combining them using fuzzy logic concepts in the proposed algorithm, we expect to be able to clearly discriminate clutter echoes from precipitation returns.

In addition to the features mentioned above (derived for each radar scan), the algorithm also takes into account the fact that some areas are more frequently affected by clutter than others. As in the algorithms proposed by Giuli et al. (1991), Lee et al. (1995), Pamment and Conway (1998), and Bellon and Kilambi (1999), we used the clutter frequency map presented above (see section $2 \mathrm{~b}$ and Fig. 2) as an additional feature of the algorithm. The role of the clutter frequency map is twofold: we have assigned it a membership function, and the bins in which clutter frequency exceeds a certain threshold (we have set it at $90 \%$ ) are labeled as clutter to ensure that most frequent clutter echoes are removed.

\section{b. Ground/sea clutter}

Because of the major differences shown in section $3 b$ between the feature distribution functions of ground and sea clutter echoes, we decided to use one configu- ration of the algorithm for identifying clutter over the ground and another for identifying it over the sea. Therefore, two different sets of membership functions $\mu_{k, e}(x)$ and two sets of weights $w_{k, e}$ were assigned to the various features.

On the other hand, visual analysis of different situations of intense AP led us to conclude that in some cases ground clutter echoes occurring near the coast extend into the first few kilometers offshore (as shown in Figs. 6a and 10a). To take this phenomenon into account, we established a $10-\mathrm{km}$ belt offshore where the algorithm has been applied using the configuration for detecting ground clutter.

\section{c. Membership functions}

Conditional probability functions $f_{k, e}(x)$ quantify the degree of confidence that an echo, where $X_{k}=x$, will be of a certain type (clutter or precipitation). This is, in fact, the purpose of membership functions. It is, therefore, intuitive that the shape of membership functions $\mu_{k, e}(x)$ should be similar to the shape of functions $f_{k, e}(x)$. Because there is some degree of subjectivity involved in producing membership functions, they are usually defined as simple curves [the most common membership functions are triangular, trapezoidal, piecewise linear, and Gaussian (Mendel 1995)]. In this study, we chose piecewise linear membership functions that reproduce the shape of the experimental functions $f_{k, e}(x)$ obtained from the analyzed dataset (see Fig. 5).

The shape of the membership functions associated with sea clutter needed to be exaggerated, with values of $\mu_{k, e}(x)$ significantly higher than $f_{k, e}(x)$ in order to produce $Y$ values high enough to detect sea clutter, whereas the joint role of these features is expected to keep the number of false alarms within acceptable limits.

\section{d. Adjustment of weights}

Table 2 shows the weights $w_{k, e}$, according to which fields $Y_{k, e}$ are averaged to derive $Y$ (some of the features for which $w_{k, e}=0$ are not used in this configuration). We obtained them by maximizing the critical success index (CSI; see, e.g., Stanski et al. 1989) over the calibration dataset. The appendix shows the results of this analysis.

It is worth noting that in this study, radial velocity measurements are only available at up to $120 \mathrm{~km}$ (see Table 1) and, therefore, we were unable to use this feature at farther distances. At these ranges, its weight is set to zero and the rest of the weights are renormalized to take this into account. However, because of the low weight assigned after the calibration process $(5 \%$ 

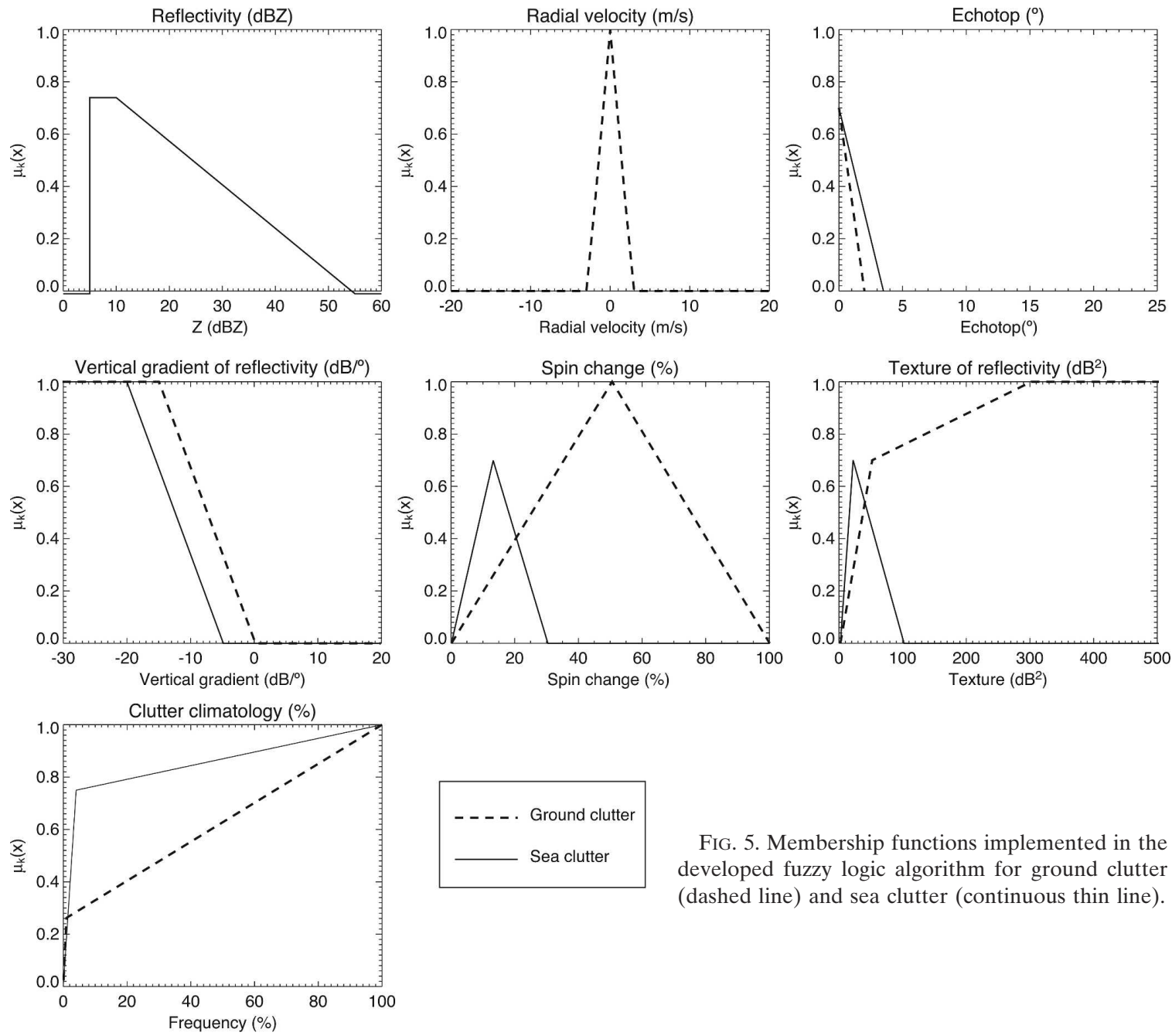

FIG. 5. Membership functions implemented in the developed fuzzy logic algorithm for ground clutter (dashed line) and sea clutter (continuous thin line).

and $0 \%$ for ground and sea clutter, respectively, see Table 2), significant differences in the performance of the algorithm are not expected between the area where Doppler measurements are available and the rest of the radar domain.

\section{e. Implementation of the algorithm in a different radar}

Smith et al. (1996) argued that one of the biggest limitations of using pixel-by-pixel AP detection algorithms is the fact that they must be recalibrated when implemented in a different radar. This usually requires a preanalyzed dataset, which sometimes does not exist (as concluded by Steiner and Smith 2002).

When implementing this algorithm in a different radar, we consider it necessary (a) to derive the clutter frequency map for the new radar domain and (b) to calibrate the set of weights according to which fields
$Y_{k, e}$ are averaged, assuming that the membership functions of Fig. 5 can be used in other radars [note the similarities between those curves and the functions proposed by Kessinger et al. (2003)].

This calibration process would thus require a preanalyzed dataset (similar to the one presented in section

TABLE 2. Weights assigned to the features implemented in the presented fuzzy logic technique.

\begin{tabular}{|c|c|c|}
\hline \multirow[b]{2}{*}{ Feature } & \multicolumn{2}{|c|}{ Weight (\%) } \\
\hline & Ground & Sea \\
\hline Reflectivity (dBZ) & 0 & 10 \\
\hline Radial velocity $\left(\mathrm{m} \mathrm{s}^{-1}\right)$ & 5 & 0 \\
\hline Spin change $(\%)$ & 15 & 5 \\
\hline Texture of reflectivity $\left(\mathrm{dB}^{2}\right)$ & 30 & 15 \\
\hline Vertical gradient of reflectivity $\left(\mathrm{dB} \mathrm{deg}^{-1}\right)$ & 15 & 20 \\
\hline Echo top (deg) & 15 & 30 \\
\hline AP climatology (\%) & 20 & 20 \\
\hline
\end{tabular}


2a). However, in order to make this process more automatic we could limit the analysis to two situations: (a) radar scans affected by precipitation measured in MP conditions where clutter can be identified using a mean clutter mask, and (b) clear-air scans taken with the radar in both MP and AP conditions, where all significant returns can be classified as clutter. This would allow us to derive the clutter frequency map and also search for the weights $w_{k, e}$ by means of an optimization analysis over the calibration dataset (as done in section 4d). Moreover, this optimization analysis would also allow us to monitor the performance of the algorithm.

\section{Results of implementation}

To illustrate the performance of the fuzzy logic algorithm, in this section we individually analyze certain characteristic examples not included in the calibration dataset. Afterward, we analyze two long series of radar scans, first in terms of the accumulated rainfall fields and then in comparison with rain gauge measurements. In both cases, we present the results obtained (a) without clutter cancellation, (b) using the mean clutter mask to identify clutter-contaminated areas, and (c) using the proposed fuzzy logic algorithm.

As mentioned above, raw radar scans are only corrected for the effect of orography beam screening before identifying nonmeteorological echoes. After removing clutter-contaminated pixels, an estimate of the weather-related reflectivity needs to be given at the resulting gaps. With this purpose, in all cases presented below (except when explicitly indicated) we have implemented the filling technique proposed by Sánchez-Diezma et al. (2001), which involves horizontal interpolation or vertical substitution depending on a simple preclassification of weather echoes.

\section{a. Example cases studies}

We corrected radar scans from three case studies using the fuzzy logic algorithm in order to illustrate its performance in a variety of meteorological situations [some additional cases are presented in Berenguer et al. (2005), and loops for all of them may be found online at http://www.grahi.upc.edu/events.php, which may help the reader discriminate between precipitation and clutter in the radar maps shown here].

\section{1) 2000 UTC 17 July 2001}

Figure 6 shows a scan with a severe AP situation, which lasted for more than $12 \mathrm{~h}$. All of the echoes of this clear-air scan corresponded to ground and sea clutter (it is worth noting that Doppler velocity is not zero over the sea, as it is in ground clutter areas). This extent was corroborated by measurements from some gauges of the Catalan Meteorologic Service [Servei Meteorològic de Catalunya (SMC)] network located in one of the areas most affected by ground clutter echoes (its location is shown in Fig. 1), which measured no rainfall from 1400 UTC 17 July 2001 to 0200 UTC 18 July 2001. Even though ground clutter affects up to the fourth tilt (see the vertical cross section in Fig. 7), the fuzzy logic algorithm was able to classify most of the echoes as clutter and only some very small nonprecipitating echoes remained after the correction (affecting only $0.1 \%$ of the radar domain after the complete QC process; see Table 3). Table 3 also shows that using the mean clutter mask to identify clutter led to considerable errors (significant conditional rainfall rates were incorrectly estimated).

\section{2) 1230 UTC 2 JANUARY 2002}

Figure 8 shows a radar scan in which a widespread precipitation system is affecting mountain ranges close to the radar (Fig. 9 shows the brightband enhancement at a height of around $2.5 \mathrm{~km}$ ). In this case, propagation is close to MP conditions, and thus only mean ground clutter echoes should be removed (such as those shown in Fig. 9, which are related to two large mountains) and precipitation echoes should remain untouched, as with the mean clutter mask. This was indeed the case, except for an echo of very low intensity and shallow vertical development located over the sea, which was erroneously removed by the fuzzy logic algorithm (shown with a dashed-line ellipse in Fig. 8c). In more quantitative terms, Table 3 illustrates the similarity between the results obtained with the fuzzy logic algorithm and those obtained using the mean clutter mask, as expected because of approximately mean propagation conditions.

\section{3) 2010 UTC 14 August 2001}

Figures 10 and 11 show a situation in which some convective cells are embedded in a stratiform system. Some sea clutter and very intense AP echoes are also affecting the southern coast, extending up to the second tilt (again, the SMC rain gauges did not measure any rain that day). The algorithm was able to discriminate most of the ground and sea clutter without affecting rainfall patterns. Only some residual echoes still remained in the vicinity of the largest clutter patterns along the southern coast. Again, Table 3 shows the impact of AP clutter on the estimated rainfall rates and the effect of the gap-filling procedure, which is crucial in areas where clutter is embedded within precipitation.

\section{b. Long series cases}

After analyzing the previously selected case studies, we found it necessary to analyze longer series of data 

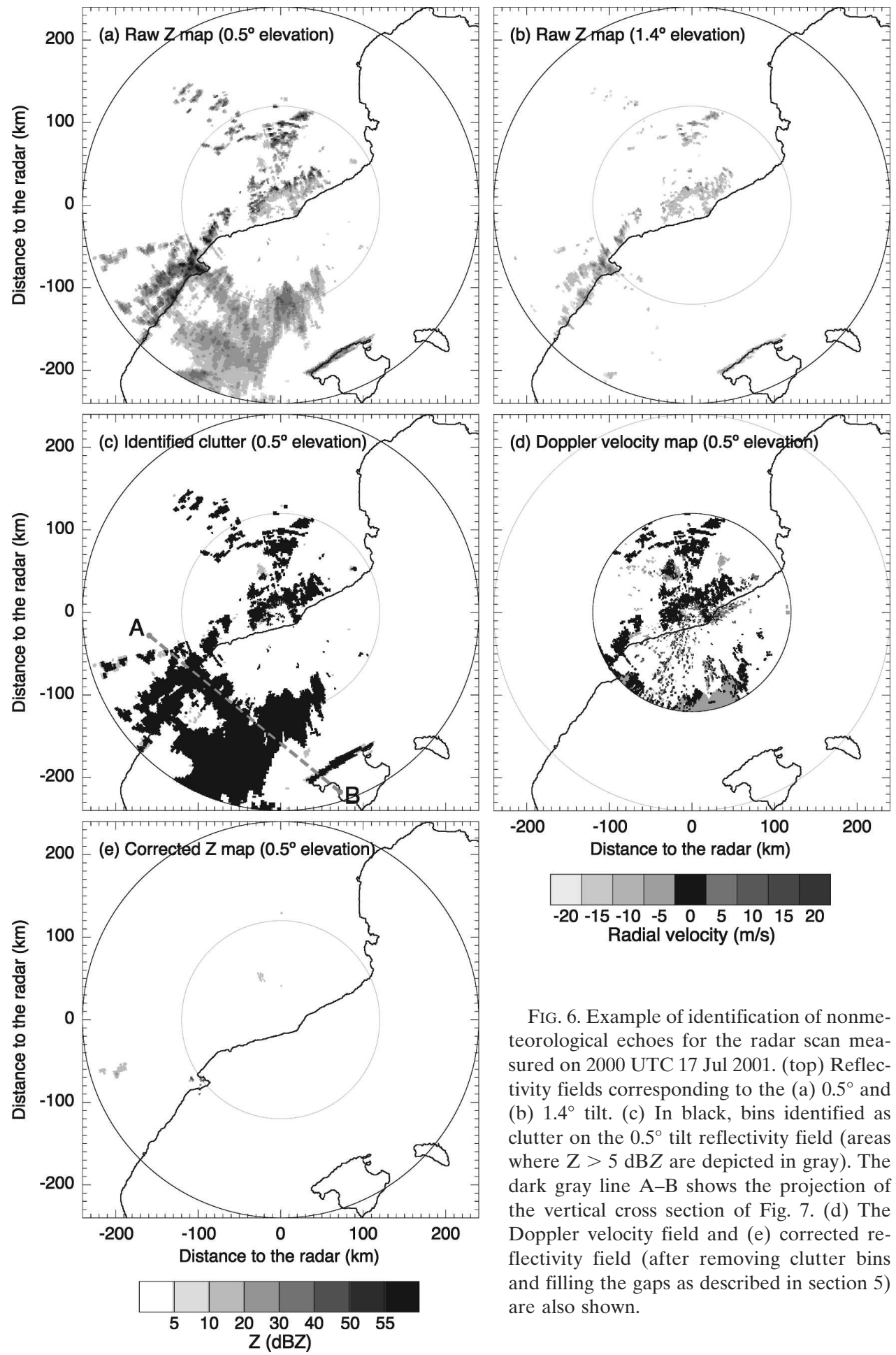

FIG. 6. Example of identification of nonmeteorological echoes for the radar scan measured on 2000 UTC 17 Jul 2001. (top) Reflectivity fields corresponding to the (a) $0.5^{\circ}$ and (b) $1.4^{\circ}$ tilt. (c) In black, bins identified as clutter on the $0.5^{\circ}$ tilt reflectivity field (areas where $\mathrm{Z}>5 \mathrm{dBZ}$ are depicted in gray). The dark gray line A-B shows the projection of the vertical cross section of Fig. 7. (d) The Doppler velocity field and (e) corrected reflectivity field (after removing clutter bins and filling the gaps as described in section 5) are also shown.

from a systematic QC perspective. In this section, the following two examples are analyzed.

- 14-19 July 2001: During the first part of this event (14-16 July 2001), a number of convective cells crossed the studied domain from southwest to northeast in the presence of significant AP. After a few hours, these cells merged into a well-organized convective system. This period was followed by 2 days without precipitation and major AP ground and sea 


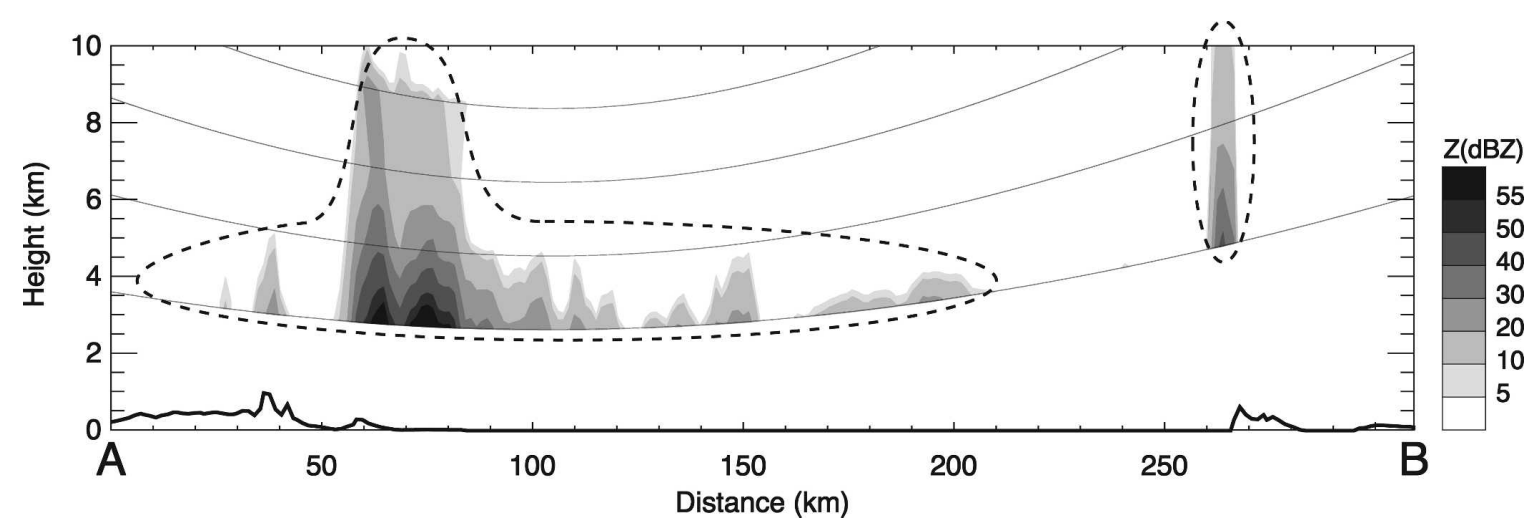

FIG. 7. Vertical cross section interpolated from volumetric radar measurements along the line A-B of Fig. $6 \mathrm{c}$ [as provided by the software Eina Hidrometeorològica Integrada (EHIMI; see Corral et al. 2004)]. Thin lines indicate radar beam paths for different tilts and thick line shows the orography profile along the section. Dashed line circles enclose most significant clutter echoes. The paths of the radar beam have been calculated supposing normal propagation conditions.

echoes (see the example in Fig. 6a). Finally, a widespread system with some embedded convection affected the area of study on 19 July 2001 (during this part of the event, the beam propagated close to the path of MP conditions).

- 1 June 2003-30 September 2003: In this case, we analyzed a dataset of around 15000 radar scans (with some gaps). Extremely high temperatures affected the domain of study during this season and precipitation was mainly caused by small convective cells [a study on storm initiation using the same radar database was carried out by Pascual et al. (2004)].
The results obtained using the various clutter correction schemes mentioned above are presented in the following two ways.

- Accumulated fields derived as the direct sum of static radar scans [see the first algorithm for rainfall accumulation described in Bellon et al. (1991), because it highlights hits and limitations of clutter cancellation algorithms]: We used a climatological $Z-R$ relationship for the studied region derived from disdrometer measurements by Sempere-Torres et al. $(1997,1998)$ to transform radar measurements into rainfall rates.

TABLE 3. Comparison of radar area, conditional and unconditional area-averaged rain rates calculated over the fields corrected using different algorithms for identifying clutter echoes and before and after applying the substitution technique.

\begin{tabular}{|c|c|c|c|}
\hline & 2000 UTC 17 Jul 2001 & 1230 UTC 2 Jan 2002 & 2010 UTC 14 Aug 2001 \\
\hline \multicolumn{4}{|c|}{ Echo area expressed as percentage of the radar domain } \\
\hline Without correction & 13.3 & 24.3 & 19.1 \\
\hline Mean clutter mask (without gap filling) & 11.1 & 22.7 & 16.9 \\
\hline Mean clutter mask + gap filling & 11.6 & 23.8 & 18.0 \\
\hline Fuzzy logic algorithm (without gap filling) & 0.0 & 22.2 & 10.0 \\
\hline Fuzzy logic algorithm + gap filling & 0.1 & 23.4 & 11.0 \\
\hline \multicolumn{4}{|c|}{ Mean rain rate conditioned to echo area $\left(\mathrm{mm} \mathrm{h}^{-1}\right)$} \\
\hline Without correction & 3.88 & 0.65 & 4.36 \\
\hline Mean clutter mask (without gap filling) & 2.76 & 0.31 & 2.92 \\
\hline Mean clutter mask + gap filling & 2.79 & 0.32 & 2.99 \\
\hline Fuzzy logic algorithm (without gap filling) & 0.00 & 0.30 & 0.85 \\
\hline Fuzzy logic algorithm + gap filling & 0.02 & 0.32 & 0.91 \\
\hline \multicolumn{4}{|c|}{ Mean rain rate calculated over the whole radar domain $\left(\mathrm{mm} \mathrm{h}^{-1}\right)$} \\
\hline Without correction & 0.52 & 0.16 & 0.83 \\
\hline Mean clutter mask (without gap filling) & 0.37 & 0.07 & 0.56 \\
\hline Mean clutter mask + gap filling & 0.37 & 0.08 & 0.57 \\
\hline Fuzzy logic algorithm (without gap filling) & 0.00 & 0.07 & 0.16 \\
\hline Fuzzy logic algorithm + gap filling & 0.00 & 0.08 & 0.17 \\
\hline
\end{tabular}



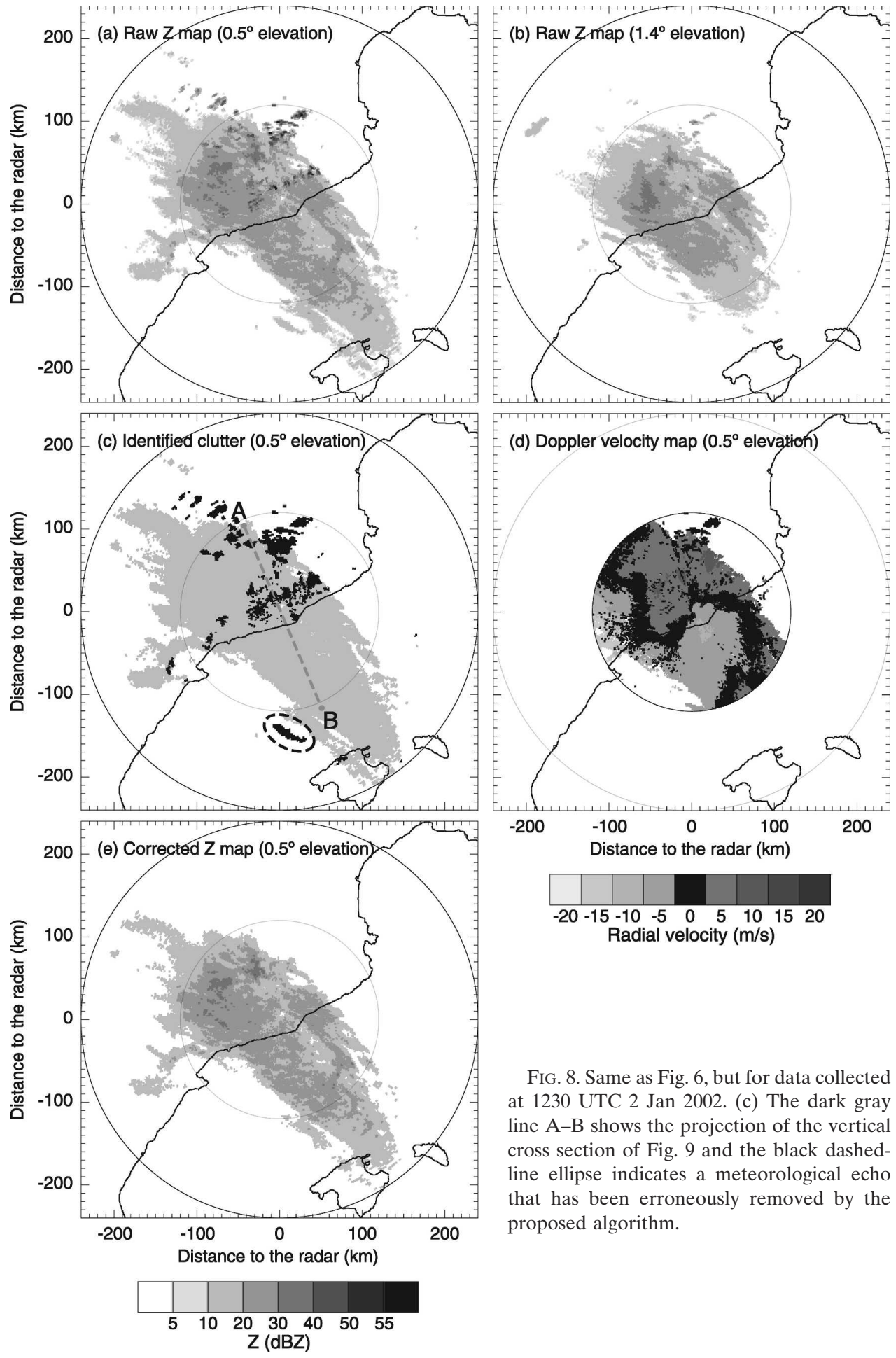

FIG. 8. Same as Fig. 6, but for data collected at 1230 UTC 2 Jan 2002. (c) The dark gray line A-B shows the projection of the vertical cross section of Fig. 9 and the black dashedline ellipse indicates a meteorological echo that has been erroneously removed by the proposed algorithm.

- In comparison with the measurements from the ACA network of rain gauges: In addition to directly comparing radar estimates and gauge measurements, we used two other indicators [already implemented by Krajewski and Vignal (2001) for the same purpose]: (a) the conditional probability of a radar observing reflectivity over $10 \mathrm{~dB} Z$ given that a collocated rain gauge measures rainfall $[P(Z>10 \mathrm{dBZ} \mid R>0$ $\mathrm{mm} \mathrm{h}^{-1}$ ), i.e., the probability of rainfall detection (POD)], and (b) the conditional probability of the 


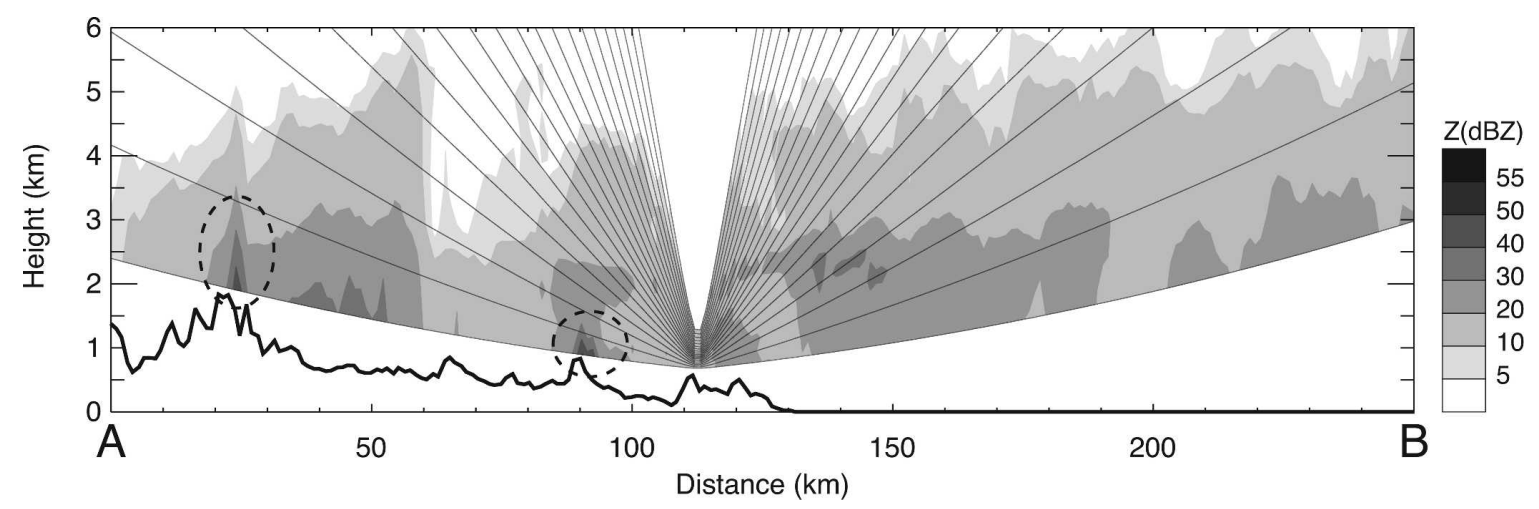

FIG. 9. Same as Fig. 7, but for the line A-B of Fig. 8c.

radar observing a significant echo, when rain gauges measure no rainfall $\left[P\left(Z>10 \mathrm{dBZ} \mid R=0 \mathrm{~mm} \mathrm{~h}^{-1}\right)\right.$, i.e., the probability of false detection (POFD)].

\section{1) 14-19 JuLy 2001}

Figure 12 shows the accumulation of the whole event in four different QC situations: (a) without removing clutter, (b) where clutter echoes have been manually identified in every scan by an expert (this will be the reference accumulation field against which the rest will be compared), (c) where echoes of the mean clutter mask have been removed, and (d) after applying the presented fuzzy logic algorithm. Used by itself, the mean clutter mask can deal neither with ground clutter associated with AP nor with sea clutter (in these areas, rainfall overestimation is not different from the overestimation observable in the accumulated field obtained with raw radar scans). Moreover, the enhancement of mean ground clutter echoes in AP conditions makes the use of the mean clutter mask significantly less useful, because major contamination affects rainfall estimates in these areas.

The proposed fuzzy logic algorithm provided better results (few differences between Figs. 12b and 12d are appreciable from visual inspection). Figure 13 shows the histograms and the mean and standard deviation of the differences between the accumulated reference field and the remainder thereof. Except for a very small number of pixels (mainly located around the mean ground echoes), the fuzzy logic algorithm identified most of the clutter, though it also produced some false alarms (i.e., some precipitation echoes were removed), mainly in regions close to areas frequently affected by clutter (the highest underestimation values were caused because the algorithm removed a small convective cell that affected the southern coast in a couple of scans). However, the differences obtained with the fuzzy logic algorithm are significantly lower than those obtained with a mean clutter mask.
As mentioned above, we also compared radar scans to the measurements from collocated rain gauges. Figure 14 shows this comparison in terms of the conditional probabilities $P\left(Z>10 \mathrm{dBZ} \mid R>0 \mathrm{~mm} \mathrm{~h}^{-1}\right)$ and $P\left(Z>10 \mathrm{dBZ} \mid R=0 \mathrm{~mm} \mathrm{~h}^{-1}\right)$ as a function of range. The POD should be high (close to 1 ); it decreases with the false alarms of the evaluated clutter-identification algorithm. Figure 14a shows the upper bound (because no radar echo has been removed). The figure shows that the POD has a tendency to decrease with range. This is mainly attributable to the following three factors (described, e.g., in Zawadzki 1984): (a) path attenuation; (b) the fact that the radar sample volume becomes bigger with the distance, which smoothes radar measurements; and (c) beam overshooting in shallow precipitation.

Clutter cancellation has a much greater effect on the POFD, which is expected to be close to zero when clutter echoes have been correctly removed [Krajewski and Vignal (2001) justified that these values could be slightly greater than zero because of the differences in the sampling volume and in the height of radar and rain gauge measurements]. Figure $14 \mathrm{~b}$ also shows that when no correction is applied (and similarly, when a mean clutter mask is used, as shown in Fig. 14f), these values are quite high. Most of them (represented as light gray squares on the graph) correspond to radar bins with a significant signal on the mean clutter map. However, some others, which are clutter free in MP conditions (black dots), show significant values of POFD, which shows the effects of AP clutter (clutter contamination can also be seen in Fig. 14e, where some light gray squares remain significantly above the range of black dots). The POFD values obtained with the fuzzy logic technique are much lower because this technique was able to remove most of the clutter (we obtained similar POFD values with the reference dataset; see Figs. 14d and $14 \mathrm{~h})$.

However, Fig. 14g shows a clear trend of light gray 

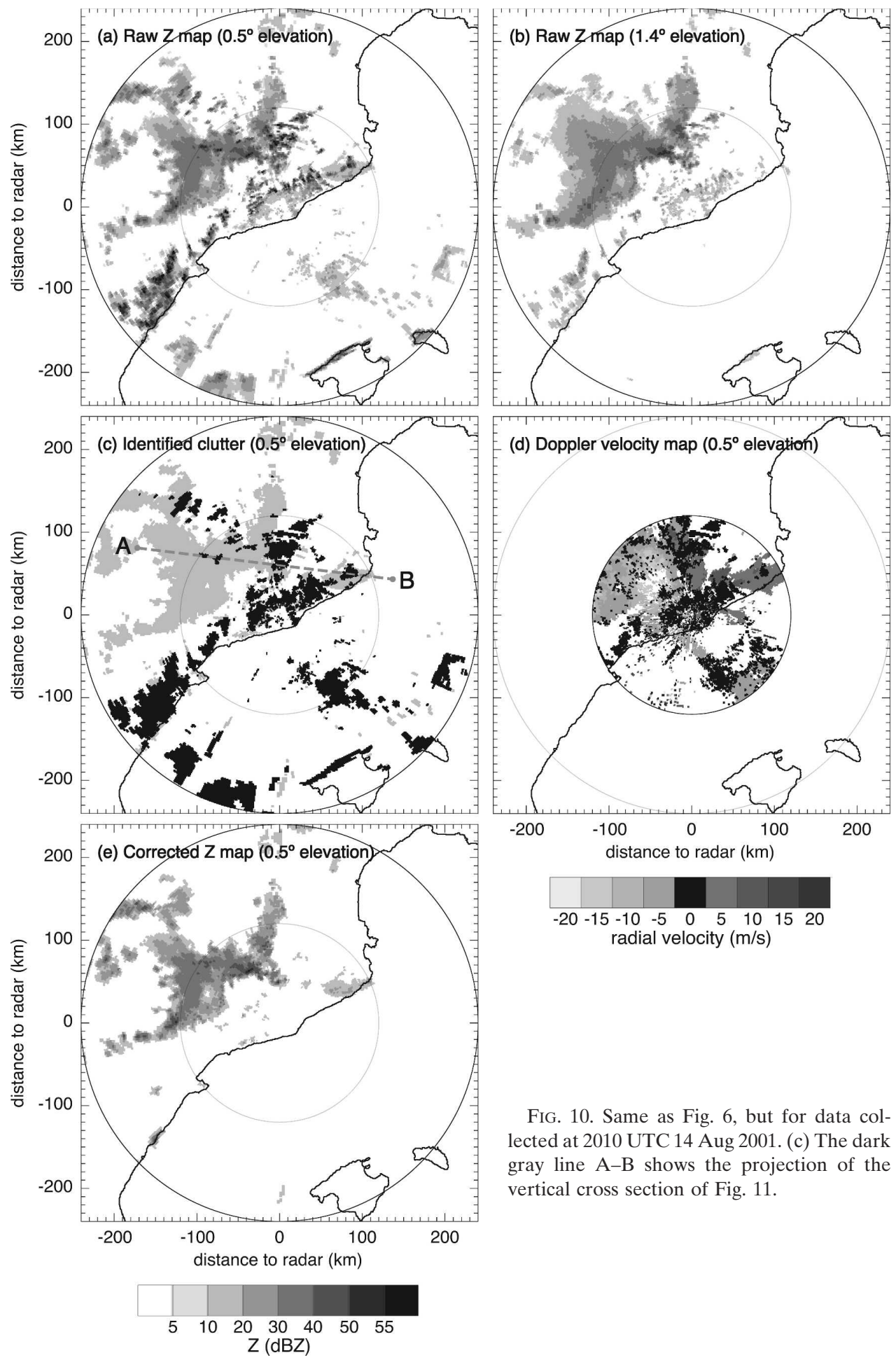

FIG. 10. Same as Fig. 6, but for data collected at 2010 UTC 14 Aug 2001. (c) The dark gray line $\mathrm{A}-\mathrm{B}$ shows the projection of the vertical cross section of Fig. 11.

squares (corresponding to rain gauges collocated with bins affected by clutter in MP conditions) at ranges between 80 and $120 \mathrm{~km}$ to present too-low POD values (with respect to the black dots). Therefore, this technique tends to underestimate rainfall at these locations.
Nevertheless, a very similar effect may also be observed in the reference POD graph shown in Fig. 14b. This phenomenon can be explained as an effect of the substitution technique used for estimating rainfall in the gaps that result from clutter elimination. All of these 


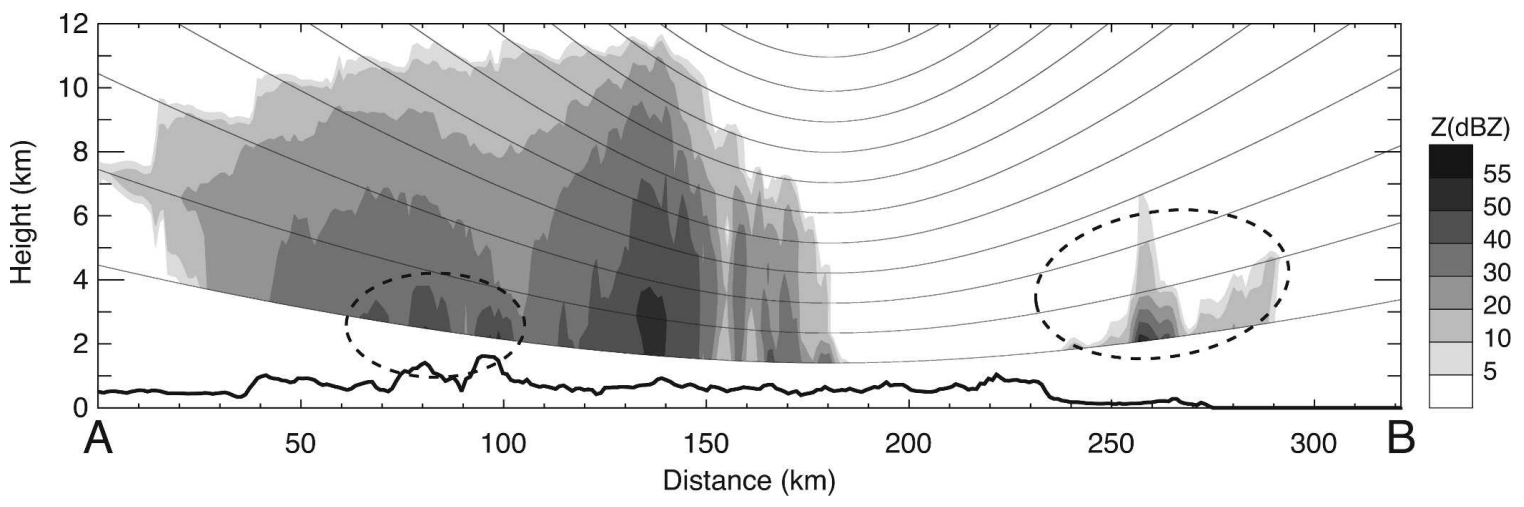

FIG. 11. Same as Fig. 7, but for the line A-B of Fig. 10c.
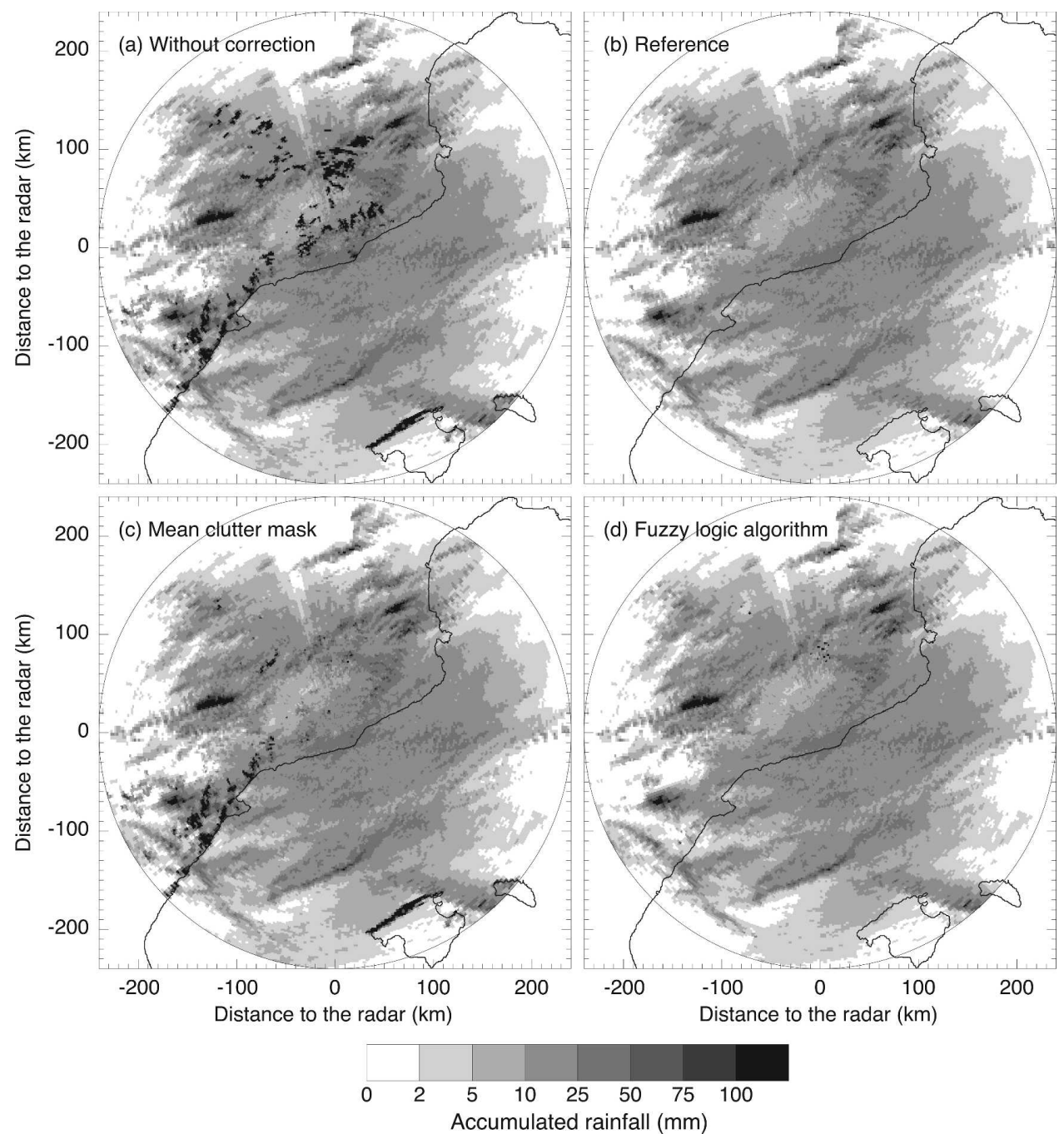

FIG. 12. Accumulated rainfall fields corresponding to the period from 0000 UTC 14 Jul 2001 to 2400 UTC 19 Jul 2001, estimated from (a) raw radar scans, (b) from corrected radar scans where clutter has been manually identified by an expert, (c) from radar scans corrected using the mean clutter mask, and (d) from radar scans corrected with the proposed fuzzy logic algorithm. 


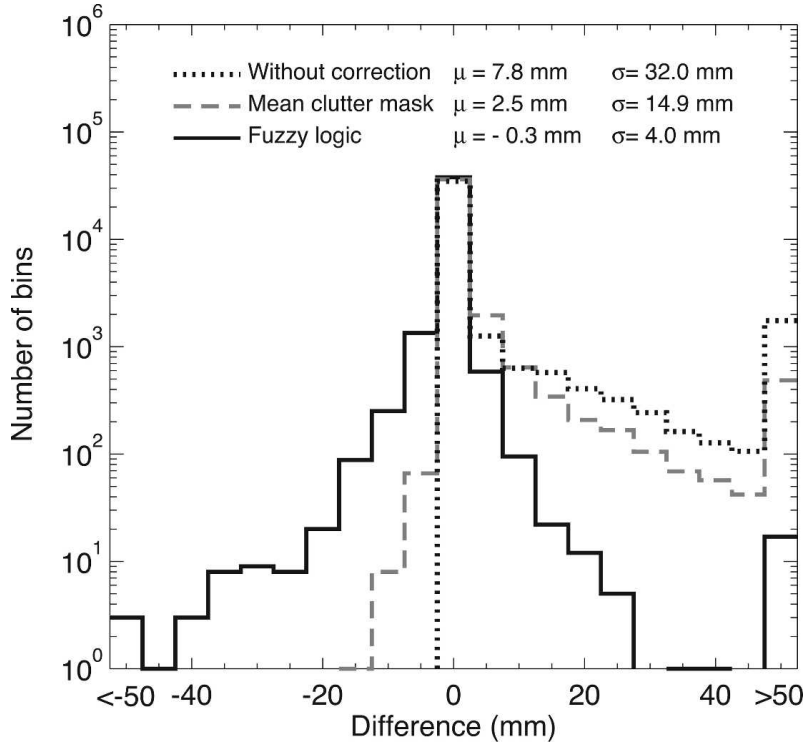

FIG. 13. Histograms of the differences between the reference accumulated field for the July 2001 event (Fig. 12b) and the accumulated field obtained when no correction is applied (Fig. 12a, dotted line), and when clutter has been automatically removed with the mean clutter mask (Fig. 12c, dashed gray line) and with the proposed fuzzy logic algorithm (Fig. 12d, continuous line).
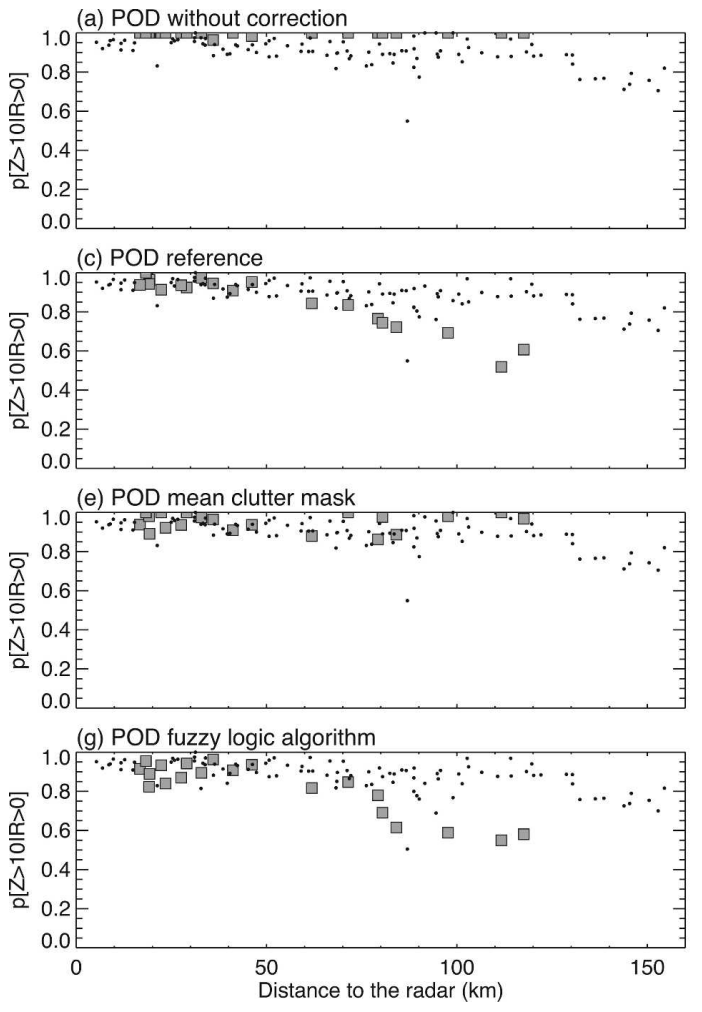

gauge-collocated bins are located on a mountain range that produces a major ground echo in MP conditions (north of the radar, enclosed by a dashed-line ellipse in Fig. 2), which makes it difficult to reconstruct precipitation, especially when rainfall patterns are small (e.g., convective cells). In this region, it may be more effective to use a substitution technique based on the reconstruction of the vertical profile of reflectivity (VPR; such as those proposed by Koistinen 1991; Joss and Lee 1995; Vignal et al. 2000 and Franco et al. 2004).

Figure 15 shows the scatterplots of the accumulated radar rainfall estimates against the gauge measurements. We can appreciate that the radar tends to underestimate accumulated rainfall (Table 4 shows that at gauge points the reference mean radar accumulation was $22.5 \mathrm{~mm}$, while the mean value registered by the gauges was $50.3 \mathrm{~mm}$ ). For the studied radar, experience shows that radome attenuation (see Sempere-Torres et al. 2003) and errors in the radar calibration may explain much of this underestimation. However, other factors that could enhance these discrepancies include path attenuation, the $Z-R$ relationship used, the effect of not considering the variation of reflectivity with height, and
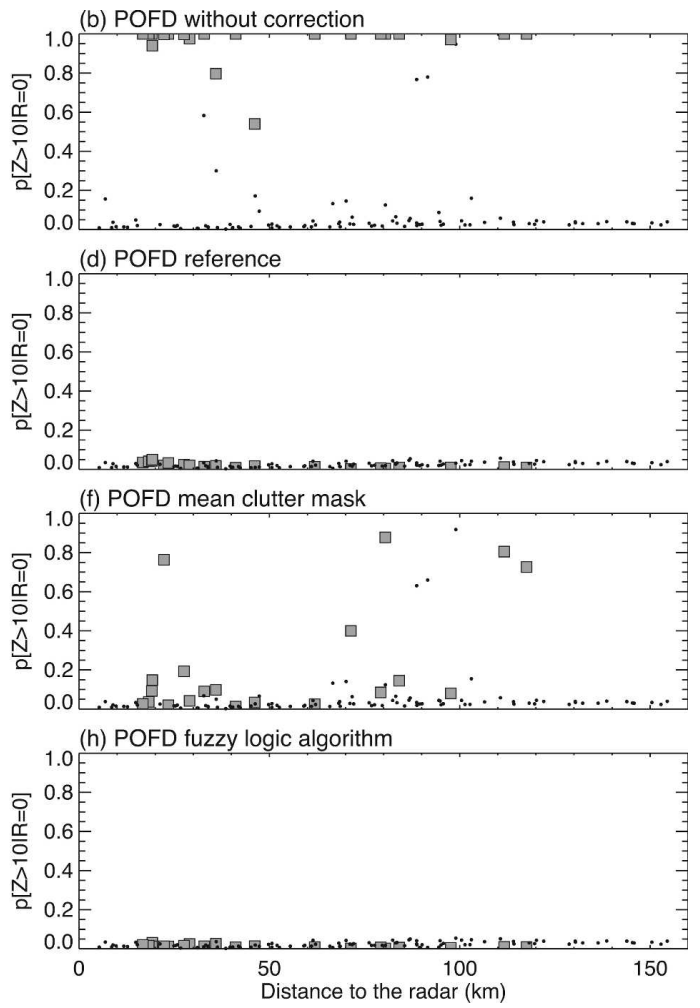

FIG. 14. (left) POD and (right) POFD conditional on the gauge measurements, corresponding to the event of 14-19 Jul 2001 when (a), (b) no correction is applied, (c), (d) clutter echoes have been removed by an expert, (e), (f) when clutter has been automatically identified with the mean clutter mask, and (g), (h) with the proposed fuzzy logic algorithm. Light gray squares correspond to rain gauges collocated with radar bins usually affected by clutter and black dots to rain gauges collocated with radar bins not affected by clutter in MP conditions. 


\section{(a) Without correction}

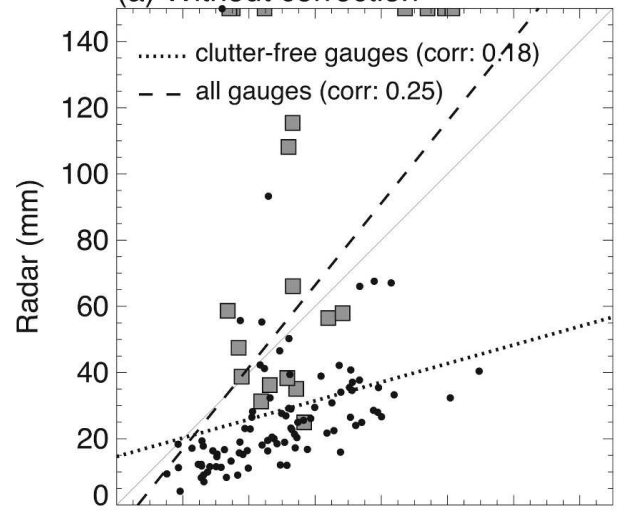

(c) Mean clutter mask

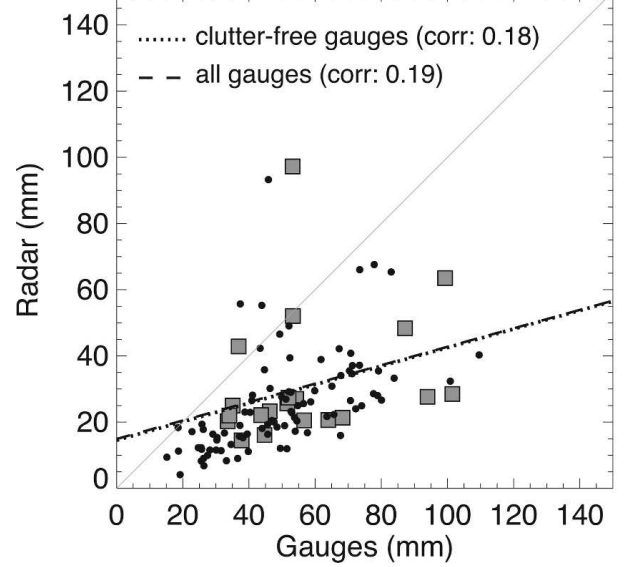

(b) Reference

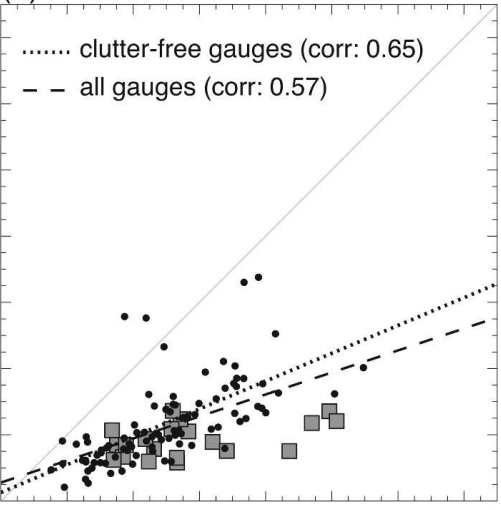

(d) Fuzzy logic algorithm

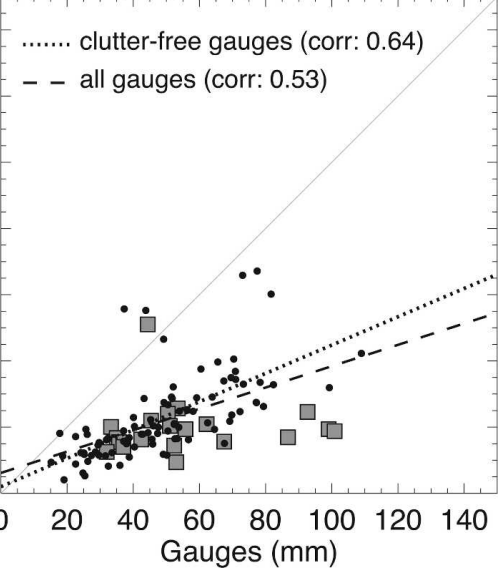

FIG. 15. Scatterplots of accumulated rain gauge rainfall measurements and estimated from radar information measured from 0000 UTC 14 Jul 2001 to 2400 UTC 19 Jul 2001. Light gray squares correspond to rain gauges collocated with radar bins usually affected by clutter and black dots to rain gauges collocated with radar bins not affected by clutter in MP conditions.

TABLE 4. Mean value and standard deviation of the rainfall accumulations calculated at gauge locations and over the whole radar domain using different algorithms for identifying clutter echoes.

\begin{tabular}{|c|c|c|c|c|c|}
\hline & Rain gauges & Without correction & Reference field & Mean clutter mask & Fuzzy logic algorithm \\
\hline \multicolumn{6}{|c|}{ At rain gauge locations } \\
\hline \multicolumn{6}{|c|}{14 Jul 2001-19 Jul 2001} \\
\hline Mean $(\mathrm{mm})$ & 50.3 & 41.4 & 22.5 & 28.4 & 22.4 \\
\hline Std dev $(\mathrm{mm})$ & 20.0 & 47.2 & 11.8 & 23.1 & 12.2 \\
\hline \multicolumn{6}{|c|}{1 Jun 2003-30 Sep 2003} \\
\hline Mean $(\mathrm{mm})$ & 148.3 & 170.6 & - & 115.7 & 67.0 \\
\hline Std dev (mm) & 65.9 & 169.8 & - & 120.8 & 51.0 \\
\hline \multicolumn{6}{|c|}{ Over the whole radar domain } \\
\hline \multicolumn{6}{|c|}{14 Jul 2001-19 Jul 2001} \\
\hline Mean (mm) & - & 14.3 & 10.5 & 12.5 & 10.3 \\
\hline $\operatorname{Std} \operatorname{dev}(\mathrm{mm})$ & - & 25.9 & 12.1 & 18.8 & 12.2 \\
\hline \multicolumn{6}{|c|}{1 Jun 2003-30 Sep 2003} \\
\hline Mean (mm) & - & 81.1 & - & 75.0 & 61.0 \\
\hline Std dev $(\mathrm{mm})$ & - & 91.5 & - & 76.8 & 41.0 \\
\hline
\end{tabular}




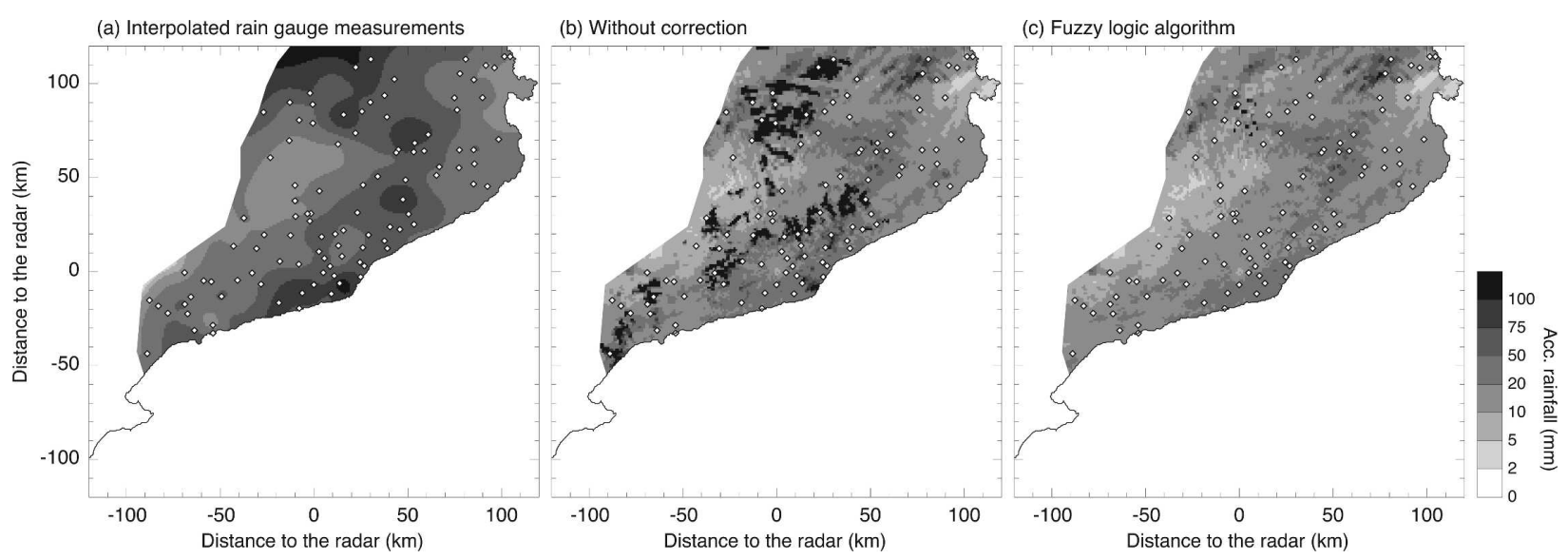

FIG. 16. Rainfall accumulation corresponding to the period from 0000 UTC 14 Jul 2001 to 2400 UTC 19 Jul 2001 (a) interpolated from the ACA rain gauge network data, and estimated from radar data (b) before removing clutter and (c) after implementing the fuzzy logic algorithm.

gauge problems. The scatterplots show a high degree of similarity between the rainfall estimates obtained with the fuzzy logic algorithm and the reference accumulation (their mean and standard deviation are also very similar, both at gauge locations and throughout the radar domain; see Table 4). In both cases, there is much less scatter than for the radar estimates obtained without clutter correction or using the mean clutter mask.

Finally, Fig. 16 also shows the accumulation field interpolated from rain gauge measurements using the thin-plate spline method jointly with the fields estimated from raw radar data and after QC with the fuzzy logic algorithm (already presented in Figs. 12a and 12d). Despite the fact that the accumulated precipitation values were generally underestimated, this comparison shows some correspondence between the accumulation patterns of the gauge-interpolated field and those of the field estimated from radar data after QC.

\section{2) 1 June-30 SePtember 2003}

This part of the study aims to evaluate the performance of the fuzzy logic algorithm when it is systematically implemented on the radar scans measured over a long period-from 1 June 2003 to 30 September 2003.

Because of the number of radar scans available for this period (around 15000 ), we were not able to manually identify clutter-contaminated bins scan by scan. However, the results shown in Figs. 17 and 18 show some similarities to the July 2001 results. The fuzzy logic algorithm was also able to remove most of the MP ground echoes and the clutter caused by AP. This was the case for most sea clutter and for the ground clutter echoes that appear frequently on the Balearic Islands and on the southern coast (Figs. 17a and 17b show that rainfall was overestimated in these areas). Again, the mean clutter mask by itself was not able to remove all of the clutter (as Fig. 18d shows, the values of POFD were too high). The low values of POFD obtained with the proposed fuzzy logic algorithm reveal a good degree of clutter rejection.

As in the July 2001 event, a similar underestimation effect related to the substitution technique can be seen after the fuzzy logic technique was applied: the light gray squares at ranges over $70 \mathrm{~km}$ (most of them located over the large ground echo shown in Fig. 2) have POD values that are too low, while most of the black dots at similar ranges remain untouched. This phenomenon is especially important in this case; in summer 2003 most rainfall events consisted of small convective cells, which are an additional difficulty for the substitution technique, mainly when they affect major clutter areas, because it is unable to reconstruct these small convective cells from a few surrounding clutter-free reflectivity measurements.

Figure 19 and Table 4 compare the accumulated radar rainfall estimates and the gauge measurements. Again, the radar-derived accumulations are significantly biased, probably because of the factors exposed above. The figure also shows the fuzzy logic algorithm's ability to reduce scatter (correlation results improved from 0.37 to 0.76 ). On the other hand, significant scatter is appreciable in the accumulation estimates obtained using the mean clutter mask, caused by remaining contamination (the standard deviation calculated at the locations of the gauges is quite high, around twice the value obtained for gauge measurements; see Table 4).

Figure 20 also presents the accumulated precipitation 


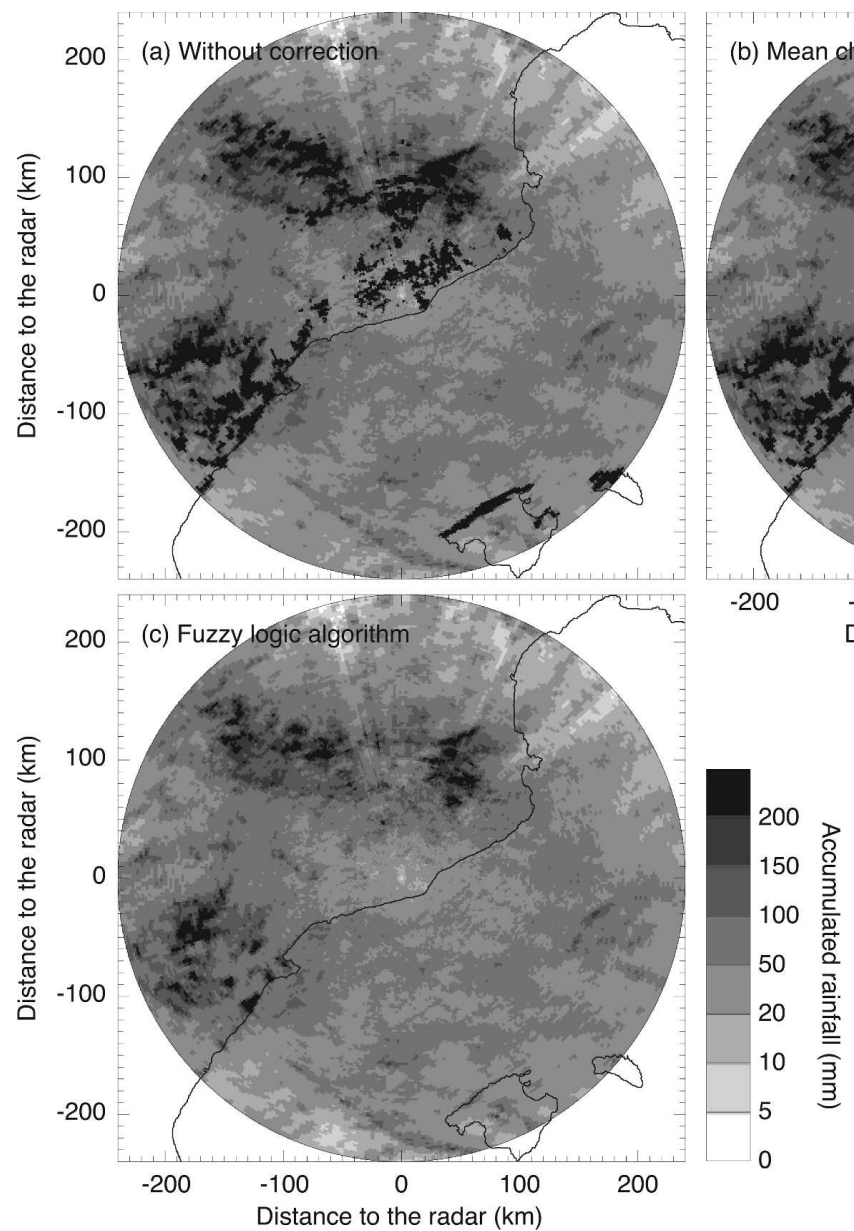

FIG. 17. Accumulated rainfall fields corresponding to the period from 0000 UTC 1 Jun 2003 to 2400 UTC 30 Sep 2003, estimated from (a) raw radar scans, (b) from radar scans corrected using the mean clutter mask, and (c) from radar scans corrected with the proposed fuzzy logic algorithm.
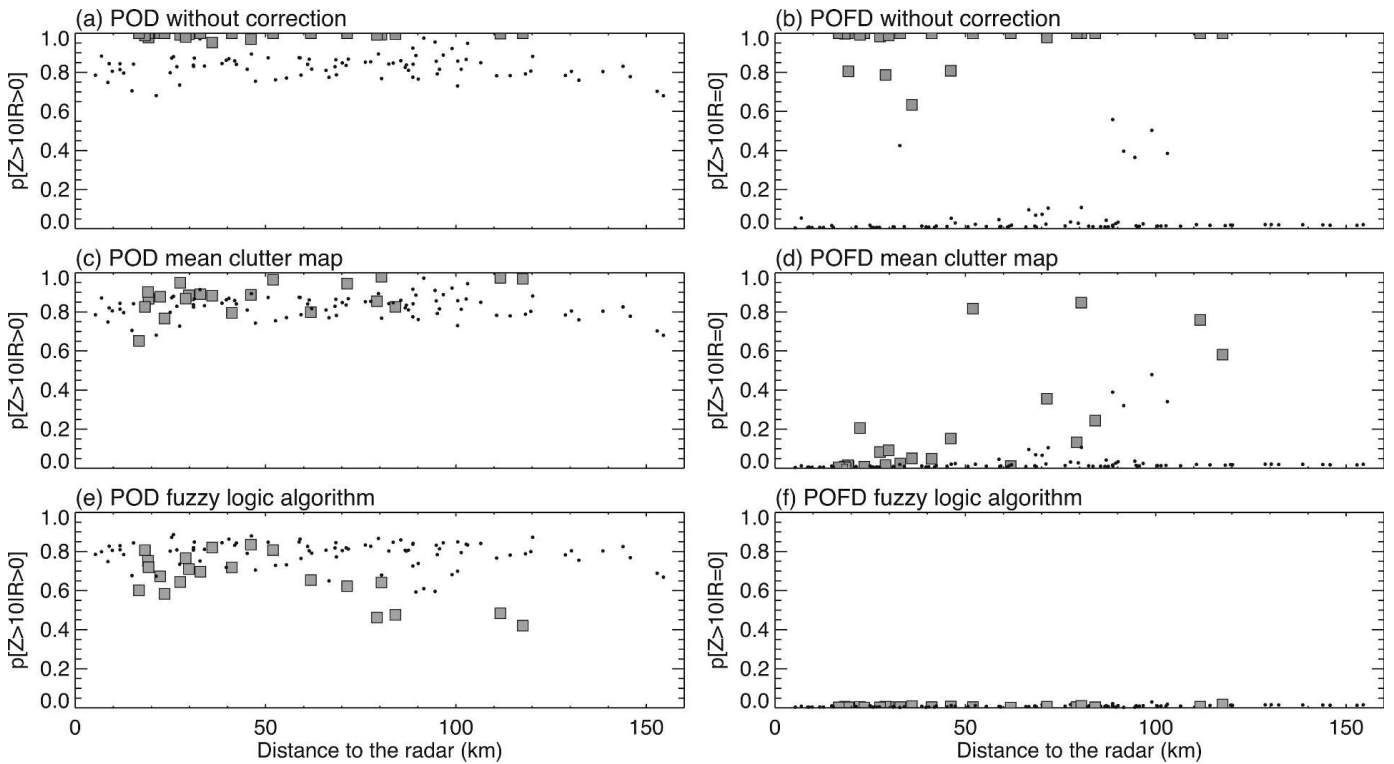

FIG. 18. (left) POD and (right) POFD conditional on the gauge measurements corresponding to summer 2003 when (a), (b) no correction is applied, and (c), (d) when clutter has been automatically identified with the mean clutter mask and (e), (f) with the proposed fuzzy logic algorithm. Light gray squares correspond to rain gauges collocated with radar bins usually affected by clutter and black dots to rain gauges collocated with radar bins not affected by clutter in MP conditions. 

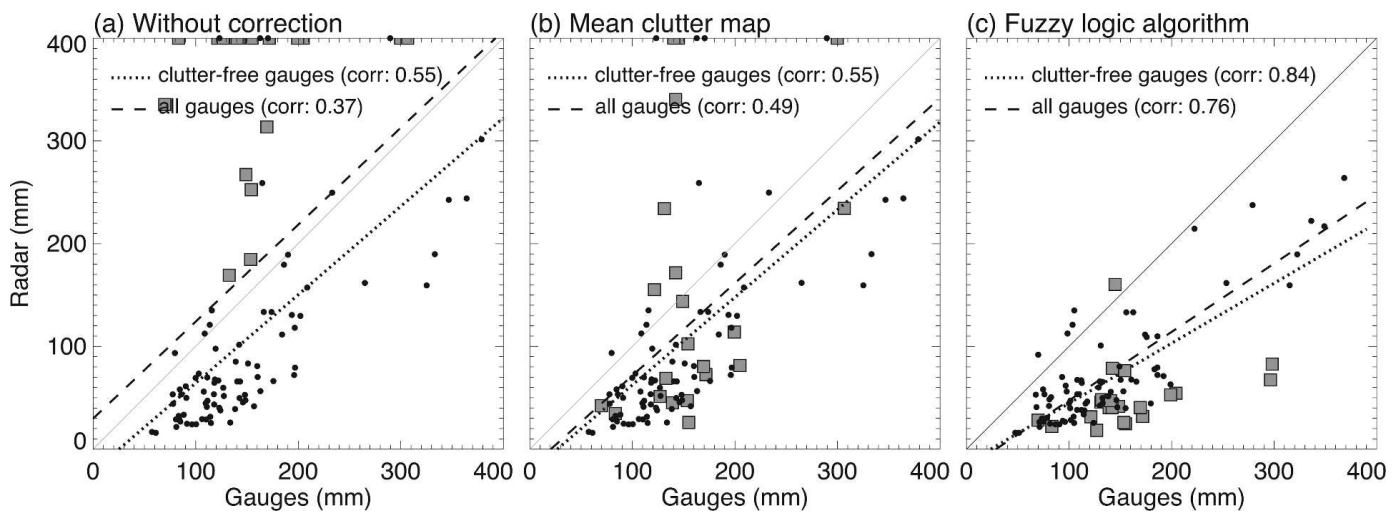

FIG. 19. Scatterplots of accumulated rain gauge rainfall measurements and estimated from radar information measured from 0000 UTC 1 Jun 2003 to 2400 UTC 30 Sep 2003. Light gray squares correspond to rain gauges collocated with radar bins usually affected by clutter and black dots to rain gauges collocated with radar bins not affected by clutter in MP conditions.

field interpolated from rain gauge measurements. In one area of Fig. 20c (around 80-110 km north of the radar), this bias is especially significant because of the aforementioned limitations of the gap-filling technique.

\section{Summary and conclusions}

In this study, we have shown the need to implement an effective clutter cancellation technique in the framework of a radar data QC scheme, especially when these data are affected by AP conditions.

Some authors have proposed using fuzzy logic concepts for clutter identification. Taking their lead, we have implemented these concepts in an algorithm that combines certain statistics that characterize clutter, derived from volumetric radar measurements (both reflectivity and radial velocity), with a prederived clutter frequency map. We found it necessary to treat ground and sea clutter separately, because they have significantly different characteristics.

The performance of the developed fuzzy logic algorithm has been studied using various characteristic radar scans representing different atmospheric and propagation situations, and it performed well, particularly for AP clutter discrimination.

We also carried out more systematic analyses using two long datasets in a context similar to operational conditions. During this part of the study, we evaluated the algorithm in terms of the rainfall accumulations estimated from radar after QC and using rain gauge measurements. The fuzzy logic algorithm showed a performance similar to that of the expert analysis and, in all cases, produced significantly better results than the mean clutter mask (which is often used when Doppler data processing is unavailable). However, the substitution technique was unable to reconstruct small precipi-

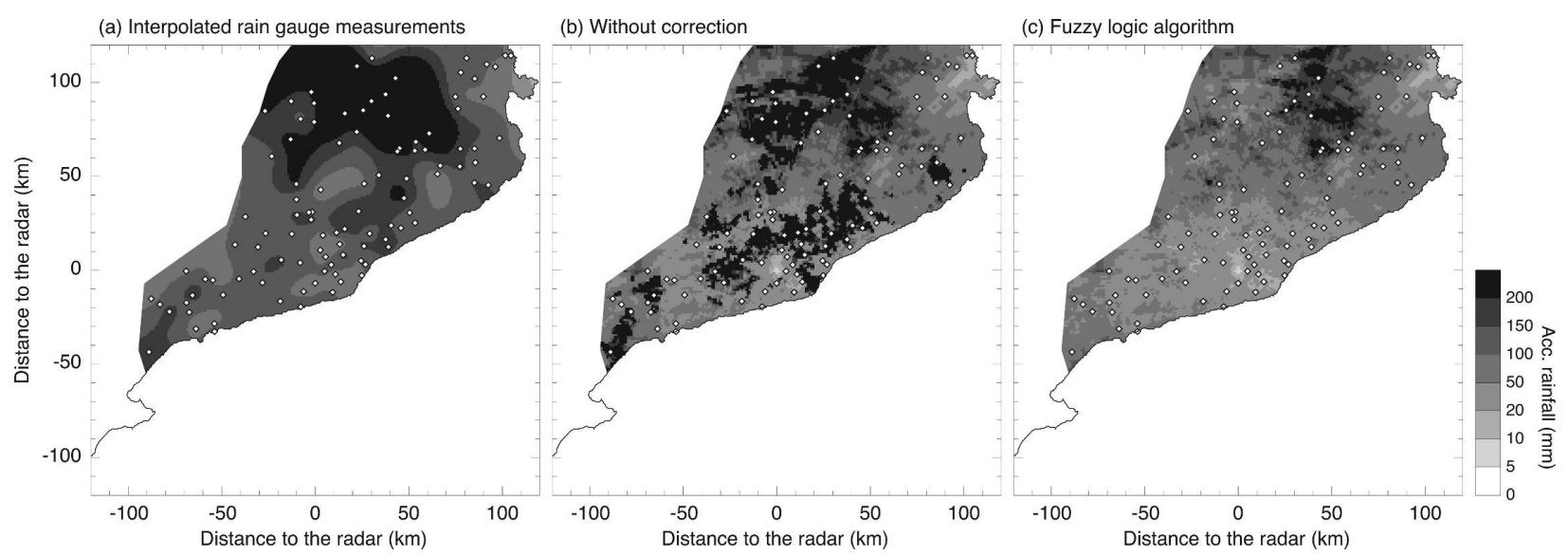

FIG. 20. Same as Fig. 16, but for the period from 0000 UTC 1 Jun 2003 to 2400 UTC 30 Sep 2003. 
tation patterns over big clutter echoes, and this effect was seen in the resulting accumulations. A VPR-based algorithm might be able to improve the performance of the technique in these areas.

The results obtained in the evaluation of the fuzzy logic algorithm encourage us to implement it in real time in the near future.

Acknowledgments. The comments of Dr. Matthias Steiner and of an anonymous reviewer helped us to significantly improve the manuscript. We also thank Dr. Remko Uijlenhoet for his preliminary review of the paper. Rubèn Domínguez identified clutter echoes in half of the calibration data set as part of his final project for the degree in Civil Engineering. Radar data were provided by the Spanish Institute of Meteorology (special thanks to Ramon Pascual) and rain gauge information was provided by the Catalan Water Agency and the Catalan Meteorological Service. This study was carried out in the framework of the EC projects VOLTAIRE (EVK2-CT-2002-00155) and FLOODSITE (GOCE-CT2004-505420).

\section{APPENDIX}

\section{Optimization of Weights $w_{k, e}$}

The weights $w_{k, e}$ according to which the fields $Y_{k, e}$ are averaged to obtain the field $Y$ (see section 4 ) were determined through a systematic study carried out over the calibration dataset, based on the optimization of the CSI for radar echoes over $10 \mathrm{dBZ}$.

We considered all possible combinations of the weights summing $100 \%$ with a resolution of $5 \%$ and allowed a maximum value of $30 \%$ (Fig. A1 shows the set of tested combinations). In this optimization process, we used the following a priori constraints to reduce the number of analyzed combinations: first, we forced the weights associated with reflectivity over the ground and with Doppler velocity over the sea to zero, because we assumed these features to have little clutter discrimination ability; and second, we set the weight associated with the clutter frequency map at $20 \%$ both over the ground and over the sea (we considered this a compromise value that makes the algorithm perform well).

The combinations that produced the best 25 CSI values are plotted with thin black lines in Fig. A1. They fall into a quite narrow area around the best combination (thick black line). However, this does not imply a high sensitivity of the CSI results to the chosen weights; Figs. A 2 and A3 show the variability of the CSI for the different tested combinations when the weight for a certain feature has been set (each point corresponds to a

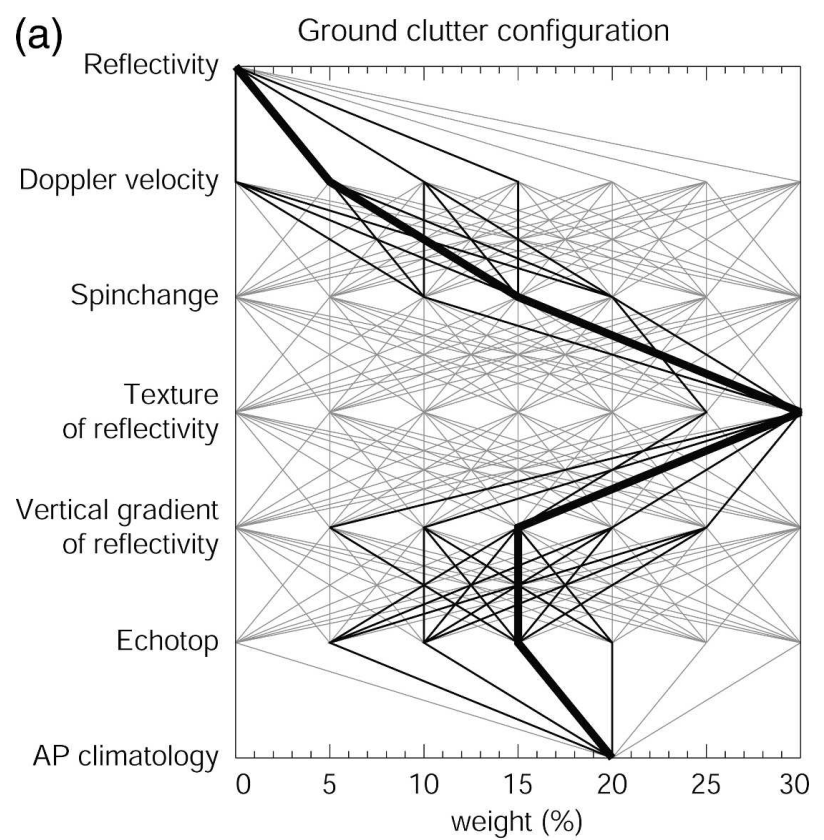

(b)

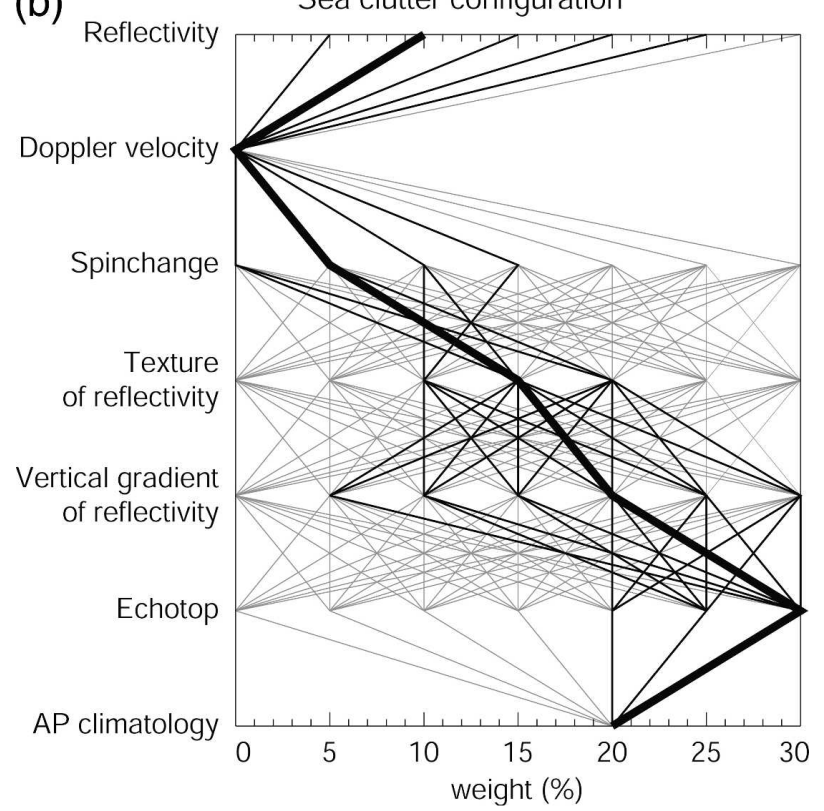

FIG. A1. Schematic representation of the CSI optimization process of the weights $w_{k, e}$ over the calibration dataset for all the configurations applied to detect (a) ground clutter and (b) sea clutter. Gray lines represent all tested combinations. Thin black lines show the 25 best combinations and the thick black lines, the best one.

combination). We can appreciate that there are many significantly different combinations of weights, both over the ground and over the sea, that produce very similar results (CSI values). CSI results for sea clutter were significantly worse, and variability was also much greater than for ground clutter (therefore, over the sea 

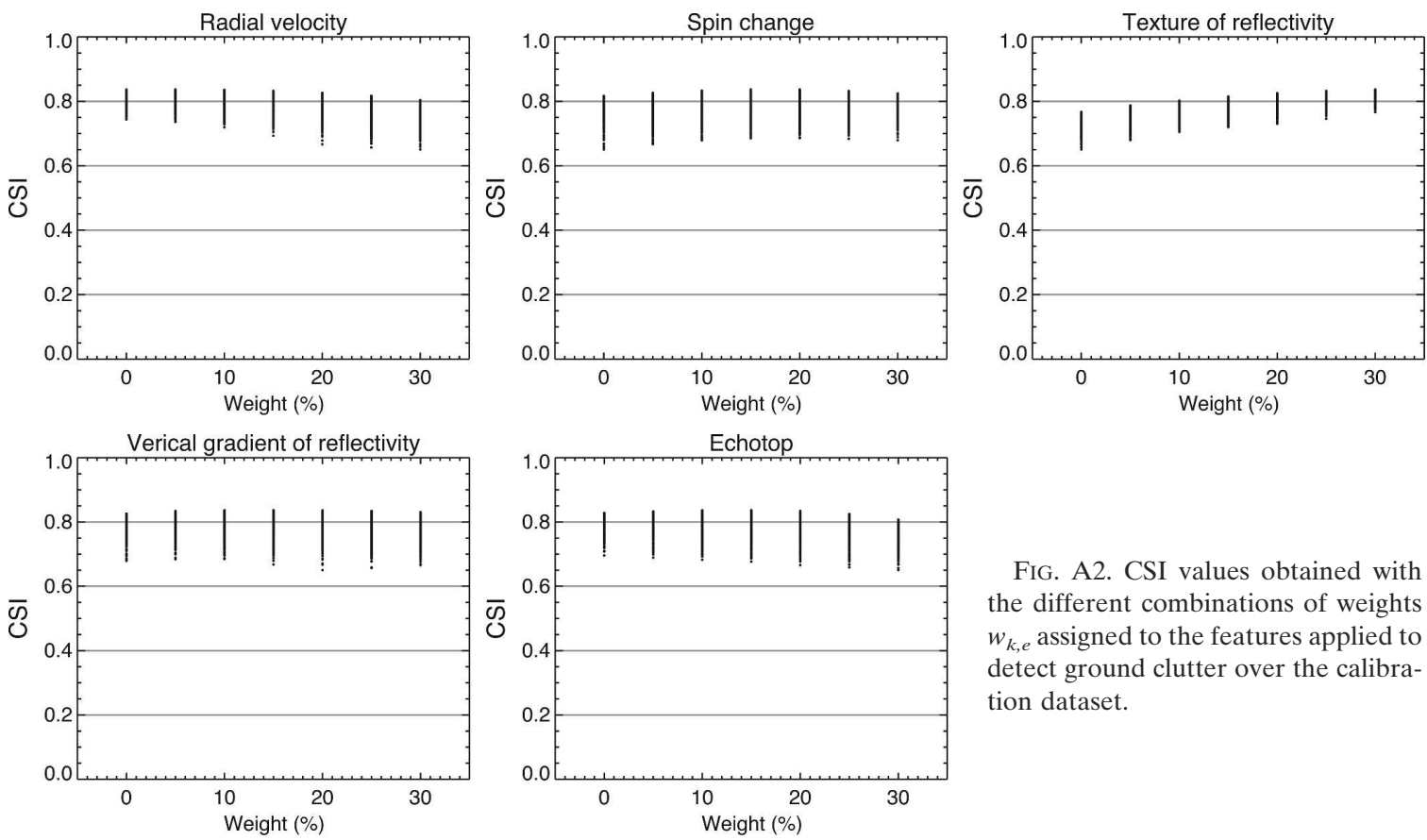

FIG. A2. CSI values obtained with the different combinations of weights $w_{k, e}$ assigned to the features applied to detect ground clutter over the calibration dataset.

the results depend more on the combination of weights chosen).

Moreover, these two figures provide information on the relative role of each feature in the performance of the algorithm. For ground clutter, the texture of reflectivity seems to be the most influencing feature (when its weight is set to zero, CSI values drop significantly), while radial velocity does not seem to play a critical role. For sea clutter all features seem to have a similar impact.

Finally, it is worth noting the not-negligible computational cost of the optimization process presented here. This can be considered a necessary limitation of the presented approach in order to achieve a satisfactory performance of the technique.
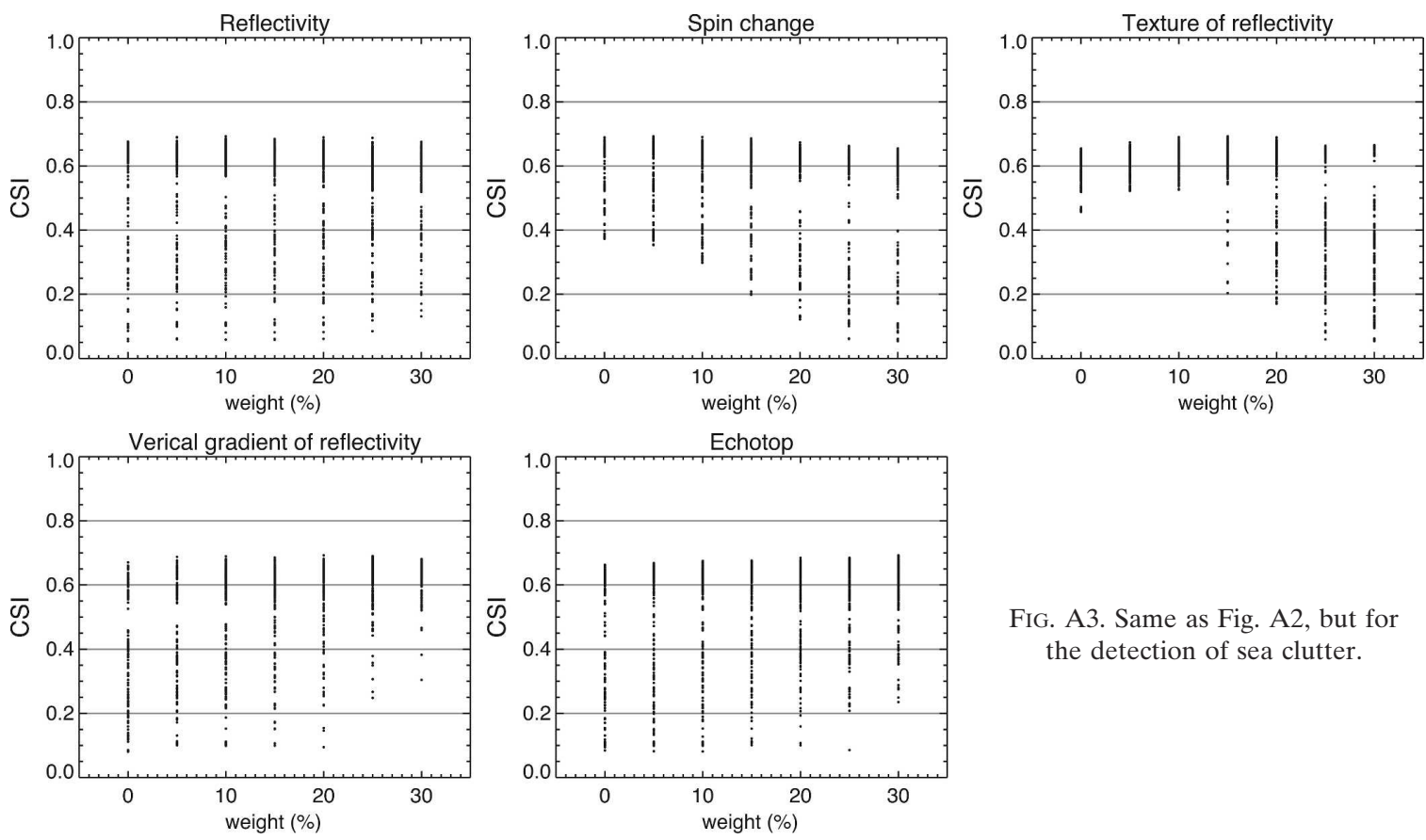

FIG. A3. Same as Fig. A2, but for the detection of sea clutter. 


\section{REFERENCES}

Andersson, T., P. P. Alberoni, P. Mezzasalma, D. B. Michelson, and S. Nanni, 1997: Anomalous propagation: Identification from terrain and sea waves using vertical reflectivity profile analysis. Preprints, 28th Conf. on Radar Meteorology, Austin, TX, Amer. Meteor. Soc., 93-94.

Aoyagi, J., 1983: A study on the MTI weather radar system for rejecting ground clutter. Pap. Meteor. Geophys., 33, 187-243.

Battan, L. J., 1973: Radar Observation of the Atmosphere. University of Chicago Press, $324 \mathrm{pp}$.

Bech, J., B. Codina, J. Lorente, and D. Bebbington, 2002: Monthly and daily variations of radar anomalous propagation conditions: How "normal" is normal propagation? Preprints, Second European Conf. on Radar Meteorology, Delft, Netherlands, Copernicus GmbH-European Meteorological Society, 35-39.

Bellon, A., and A. Kilambi, 1999: Updates to the McGill RAPID (Radar Data Analysis, Processing and Interactive Display) system. Preprints, 29th Int. Conf. on Radar Meteorology, Montreal, QC, Canada, Amer. Meteor. Soc., 121-124.

_ - F. Fabry, and G. L. Austin, 1991: Errors due to space/time sampling strategies in high resolution radar data used in hydrology. Preprints, 25th Int. Conf. on Radar Meteorology, Paris, France, Amer. Meteor. Soc., 840-843.

Berenguer, M., D. Sempere-Torres, R. Sánchez-Diezma, and R. Pascual, 2005: Identification of clutter echoes using a fuzzy logic technique. Preprints, 32d Conf. on Radar Meteorology, Albuquerque, NM, Amer. Meteor. Soc., CD-ROM, P4R.1.

Corral, C., D. Sempere-Torres, C. Velasco, R. Sánchez-Diezma, M. Berenguer, E. Velasco, and J. Pastor, 2004: EHIMI: Herramienta de previsión hidrometeorológica integrada. Experiencia y resultados de la primera fase de implementación en Catalunya (in Spanish). Preprints, Jornadas sobre los Sistemas de Ayuda a la Decisión ante Problemas Hidráulicos e Hidrológicos en Tiempo Real, Madrid, Spain, CEDEX, 279287.

da Silveira, R. B., and A. R. Holt, 2001: An automatic identification of clutter and anomalous propagation in polarizationdiversity weather radar data using neural networks. IEEE Trans. Geosci. Remote Sens., 39, 1777-1788.

Delrieu, G., and J. D. Creutin, 1995: Simulation of radar mountain returns using a digitized terrain model. J. Atmos. Oceanic Technol., 12, 1038-1049.

Doviak, R. J., and D. S. Zrnic, 1992: Doppler Radar and Weather Observations. $2 \mathrm{~d}$ ed. Academic Press, 562 pp.

Fabry, F., C. Frush, I. Zawadzki, and A. Kilambi, 1997: On the extraction of near-surface index of refraction using radar phase measurements from ground targets. J. Atmos. Oceanic Technol., 14, 978-987.

Fiore, J. V., R. K. Farnsworth, and G. Huffman, 1986: Quality control of radar-rainfall data with VISSR satellite data. Preprints, 23d Conf. on Radar Meteorology and Conf. on Cloud Physics, Snowmass, CO, Amer. Meteor. Soc., JP15-JP18.

Franco, M., D. Sempere-Torres, R. Sánchez-Diezma, and H. Andrieu, 2004: Improvements in weather radar rain rate estimates at the ground using a methodology to identify the vertical profile of reflectivity from volume radar scans. Preprints, Third European Conf. on Radar Meteorology and Hydrology, Visby, Sweden, Copernicus GmbH-European Meteorological Society, 368-373.

Fulton, R. A., J. P. Breidenbach, D.-J. Seo, D. A. Miller, and
T. D. O'Bannon, 1998: The WSR-88D rainfall algorithm. Wea. Forecasting, 13, 377-395.

Giuli, D., M. Gherardelli, A. Freni, T. A. Seliga, and K. Aydin, 1991: Rainfall and clutter discrimination by means of duallinear polarization radar measurements. J. Atmos. Oceanic Technol., 8, 777-789.

Grecu, M., and W. E. Krajewski, 2000: An efficient methodology for detection of anomalous propagation echoes in radar reflectivity data using neural networks. J. Atmos. Oceanic Technol., 17, 121-129.

Hannesen, R., 2001: Quantitative precipitation estimation from radar data-A review of current methodologies. MUSIC European Commission Project, Deliverable 4.1, 31 pp.

Joss, J., and A. Waldvogel, 1990: Precipitation measurements and hydrology. Radar in Meteorology: Battan Memorial and 40th Anniversary of the Radar Meteorology Conference, D. Atlas, Ed., Amer. Meteor. Soc., 577-606.

_ and R. Lee, 1995: The application of radar-gauge comparisons to operational precipitation profiles corrections. J. Appl. Meteor., 34, 2612-2630.

Keeler, R. J., and R. Passarelli, 1990: Signal processing for atmospheric radars. Radar in Meteorology: Battan Memorial and 40th Anniversary of the Radar Meteorology Conference, D. Atlas, Ed., Amer. Meteor. Soc., 199-229.

Kessinger, C., S. Ellis, and J. Van Andel, 2001: NEXRAD data quality: The AP clutter mitigation scheme. Preprints, 30th Int. Conf. on Radar Meteorology, Munich, Germany, Amer. Meteor. Soc., 707-709.

— — - and _ 2003: The radar echo classifier: A fuzzy logic algorithm for the WSR-88D. Preprints, Third Conf. on Artificial Intelligence Applications to the Environmental Science, Long Beach, CA, Amer. Meteor. Soc., 1-11.

Koistinen, J., 1991: Operational correction of radar rainfall errors due to the vertical profile of reflectivity. Preprints, 25th Int. Conf. on Radar Meteorology, Paris, France, Amer. Meteor. Soc., 91-96.

Kosko, B., 1992: Neural Networks and Fuzzy Systems: A Dynamical Systems Approach to Machine Intelligence. Prentice Hall, 449 pp.

Krajewski, W. F., and B. Vignal, 2001: Evaluation of anomalous propagation echo detection in WSR-88D data: A large sample case study. J. Atmos. Oceanic Technol., 18, 807-814.

Kulie, M. S., M. Robinson, D. A. Marks, B. S. Ferrier, D. Rosenfeld, and D. B. Wolff, 1999: Operational processing of ground validation data for the Tropical Rainfall Measuring Mission. Preprints, 29th Int. Conf. on Radar Meteorology, Montreal, QC, Canada, Amer. Meteor. Soc., 736-739.

Lee, G. W., Y.-H. Cho, K.-E. Kim, and I. Zawadzki, 2005: Identification and removal of non-precipitation echoes using the characteristics of radar echoes. Preprints, $32 d$ Conf. on Radar Meteorology, Albuquerque, NM, Amer. Meteor. Soc., CDROM, 4R.3.

Lee, R., G. Della Bruna, and J. Joss, 1995: Intensity of ground clutter and of echoes of anomalous propagation and its elimination. Preprints, 27th Conf. on Radar Meteorology, Vail, CO, Amer. Meteor. Soc., 651-652.

Martín, F., and L. de Esteban, 1994: Manual de interpretación radar (in Spanish). Instituto Nacional de Meteorología, 97 pp.

Meischner, P., C. G. Collier, A. Illingworth, J. Joss, and W. Randeu, 1997: Advanced weather radar systems in Europe: The COST 75 Action. Bull. Amer. Meteor. Soc., 78, 1411-1430. 
Mendel, J. M., 1995: Fuzzy logic systems for engineering: A tutorial. Proc. IEEE, 83, 345-377.

Michelson, D. B., and T. Andersson, 1995: Identification and suppression of anomalous propagation echoes in two-dimensional radar images. Preprints, 27th Conf. on Radar Meteorology, Vail, CO, Amer. Meteor. Soc., 656-658.

Moszkowicz, S., G. J. Ciach, and W. F. Krajewski, 1994: Statistical detection of anomalous propagation in radar reflectivity patterns. J. Atmos. Oceanic Technol., 11, 1026-1034.

Nicol, J. C., P. Tabary, J. Sugier, J. Parent-du-Chatelet, and G. Delrieu, 2003: Non-weather echo identification for conventional operational radar. Preprints, 31st Conf. on Radar Meteorology, Seattle, WA, Amer. Meteor. Soc., 542-545.

Pamment, J. A., and B. J. Conway, 1998: Objective identification of echoes due to anomalous propagation in weather radar data. J. Atmos. Oceanic Technol., 15, 98-113.

Pascual, R., R. Callado, and M. Berenguer, 2004: Convective storm initiation in central Catalonia. Preprints, Third European Conf. on Radar Meteorology and Hydrology, Visby, Sweden, Copernicus GmbH-European Meteorological Society, 464-468.

Pratte, F., R. Gagnon, and R. Cornelious, 1993: Ground clutter characteristics and residue mapping. Preprints, 26th Conf. on Radar Meteorology, Norman, OK, Amer. Meteor. Soc., 5052.

, R. J. Keeler, R. Gagnon, and D. Sirmans, 1995: Clutter processing during anomalous propagation conditions. Preprints, 27th Conf. on Radar Meteorology, Vail, CO, Amer. Meteor. Soc., 139-141.

—, D. Ecoff, J. VanAndel, and R. Jeffrey Keeler, 1997: AP clutter mitigation in the WSR-88D. Preprints, 28th Conf. on Radar Meteorology, Austin, TX, Amer. Meteor. Soc., 504507.

Rosenfeld, D., E. Amital, and D. B. Wolff, 1995: Classification of rain regimes by the three dimensional properties of reflectivity fields. J. Appl. Meteor., 34, 198-211.

Ryzhkov, A. V., and D. S. Zrnic, 1998: Polarimetric rainfall estimation in the presence of anomalous propagation. J. Atmos. Oceanic Technol., 15, 1320-1330.

Sánchez-Diezma, R., D. Sempere-Torres, G. Delrieu, and I. Zawadzki, 2001: An Improved methodology for ground clutter substitution based on a pre-classification of precipitation types. Preprints, 30th Int. Conf. on Radar Meteorology, $\mathrm{Mu}-$ nich, Germany, Amer. Meteor. Soc., 271-273.

Sempere-Torres, D., J. M. Porrà, and J. D. Creutin, 1997: Characterization of rainfall properties using the Drop Size Distribution: Application to autumn storms in Barcelona. Preprints, WMO-INM Int. Conf. on Cyclones and Hazardous Weather in the Mediterranean Area, Palma de Mallorca, Spain, Instituto Nacional de Meteorología, 621-628.

,-- , and — 1998: Experimental evidence of a general description for raindrop size distribution properties. J. Geophys. Res., 103, 1785-1797.

- R. Sánchez-Diezma, M. Berenguer, R. Pascual, and I. Zawadzki, 2003: Improving radar rainfall measurement stability using mountain returns in real time. Preprints, 31st Conf. on Radar Meteorology, Seattle, WA, Amer. Meteor. Soc., 220-221.

Smith, J. A., M. L. Baeck, M. Steiner, B. Bauer-Messmer, W. Zhao, and A. Tapia, 1996: Hydrometeorological assessments of the NEXRAD rainfall algorithms. NOAA National Weather Service Final Report, 59 pp.

Stanski, H. R., L. J. Wilson, and W. R. Burrows, 1989: Survey of common verification methods in meteorology. World Meteorological Organization World Weather Watch Tech. Rep. 8, $114 \mathrm{pp}$.

Steiner, M., and J. A. Smith, 2002: Use of three-dimensional reflectivity structure for automated detection and removal of non-precipitating echoes in radar data. J. Atmos. Oceanic Technol., 19, 673-686.

$\longrightarrow,-$ C. Kessinger, and B. S. Ferrier, 1999: Evaluation of algorithm parameters for radar data quality control. Preprints, 29th Conf. on Radar Meteorology, Montreal, QC, Canada, Amer. Meteor. Soc., 582-585.

Vignal, B., G. Galli, J. Joss, and U. Germann, 2000: Three methods to determine profiles of reflectivity from volumetric radar data to correct precipitation estimates. J. Appl. Meteor., 39, 1715-1726.

Weber, M. E., M. L. Stone, and J. A. Cullen, 1993: Anomalous propagation associated with thunderstorm outflows. Preprints, 26th Conf. on Radar Meteorology, Norman, OK, Amer. Meteor. Soc., 238-240.

Zawadzki, I., 1984: Factors affecting the precision of radar measurement of rain. Preprints, 22d Conf. on Radar Meteorology, Zurich, Switzerland, Amer. Meteor. Soc., 251-256. 